\title{
2003 North American interagency intercomparison of ultraviolet spectroradiometers: scanning and spectrograph instruments
}

\author{
Kathleen Lantz, ${ }^{\text {a }}$ Patrick Disterhoft, ${ }^{\text {a }}$ James Slusser, ${ }^{\mathrm{e}}$ Wei Gao, ${ }^{\mathrm{e}}$ Jerry \\ Berndt, ${ }^{\mathrm{b}}$ Germar Bernhard, ${ }^{\mathrm{c}}$ Sarah Bloms, ${ }^{\mathrm{a}}$ Rocky Booth, ${ }^{\mathrm{c}}$ James \\ Ehramjian, ${ }^{\mathrm{c}}$ Lee Harrison, ${ }^{\mathrm{b}}$ George Janson, ${ }^{\mathrm{e}}$ Paul Johnston, ${ }^{\mathrm{d}}$ Piotr \\ Kiedron, ${ }^{\text {a,b }}$ Richard McKenzie, ${ }^{\mathrm{d}}$ Michael Kimlin, ${ }^{\mathrm{g}, \mathrm{j}}$ Patrick Neale, ${ }^{\mathrm{h}}$

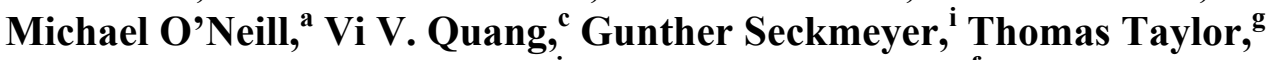 \\ Sigrid Wuttke, and Joseph Michalsky ${ }^{\mathrm{f}}$ \\ a Cooperative Institute for Research in Environmental Studies, University of Colorado, \\ Boulder, CO 80309, USA \\ ${ }^{\mathrm{b}}$ Atmospheric Sciences Research Center, State University of New York, Albany, 251 Fuller \\ Road, Albany, NY 12203, USA \\ ${ }^{c}$ Biospherical Instruments Inc., 5340 Riley Street, San Diego, CA 92110-2621, USA \\ ${ }^{d}$ National Institute of Water and Atmospheric Research, Lauder, New Zealand \\ ${ }^{\mathrm{e}}$ US Department of Agriculture UV-B Monitoring and Research Program, Colorado State \\ University, Fort Collins, CO 80523 \\ ${ }^{\mathrm{f}}$ National Oceanic and Atmospheric Administration, Earth System Research Laboratory, 325 \\ Broadway, Boulder, CO, 80303, USA \\ ${ }^{\mathrm{g}}$ formerly, National Ultraviolet Monitoring Center, University of Georgia, Athens, GA \\ 30602, USA \\ ${ }^{\text {h }}$ Smithsonian Environmental Research Center, P.O. Box 28, Edgewater, MD 21037, USA \\ ${ }^{i}$ Institute of Meteorology and Climatology, University of Hannover, Herrenhaeuser Str. 2, \\ 30419, Hannover, Germany \\ ${ }^{\mathrm{j}}$ Queensland University of Technology, Australian Sun and Health Research, Queensland, \\ Australia
}

\begin{abstract}
The fifth North American Intercomparison of Ultraviolet Monitoring Spectroradiometers was held June 13 to 21, 2003 at Table Mountain outside of Boulder, Colorado, USA. The main purpose of the Intercomparison was to assess the ability of spectroradiometers to accurately measure solar ultraviolet irradiance, and to compare the results between instruments of different monitoring networks. This Intercomparison was coordinated by NOAA and included participants from six national and international agencies. The UV measuring instruments included scanning spectroradiometers, spectrographs, and multi-filter radiometers. Synchronized spectral scans of the solar irradiance were performed between June 16 and 20, 2003. The spectral responsivities were determined for each instrument using the participants' lamps and calibration procedures and with NOAA/CUCF standard lamps. This paper covers the scanning spectroradiometers and the one spectrograph. The solar irradiance measurements from the different instruments were deconvolved using a high resolution extraterrestrial solar irradiance and reconvolved with a 1-nm triangular bandpass to account for differences in the bandwidths of the instruments. The measured solar irradiance from the spectroradiometers using the rivmSHIC algorithm on a clear-sky day on DOY 172 at $17.0 \mathrm{UTC}\left(\mathrm{SZA}=30^{\circ}\right)$ had a relative $1-\sigma$ standard deviation of $+/-2.6$ to $3.4 \%$ for 300- to 360-nm using the participants' calibration.
\end{abstract}

Keywords: spectroradiometer, filter radiometer, ultraviolet, intercomparison. 


\section{INTRODUCTION}

Solar ultraviolet (UV) radiation has known adverse and beneficial effects on human health, the terrestrial and aquatic biosphere, and man-made materials. In humans, excess UV levels are known to contribute to skin cancer, erythema, cataracts, cornea damage, and immune system suppression; but UV levels are also important for Vitamin D production [1]. Ultraviolet radiation drives photochemical reactions in the atmosphere and therefore is an important quantity for air quality studies. The impacts of solar ultraviolet (UV) radiation on biological ecosystems, human health, and materials has resulted in government agencies around the world developing UV Monitoring Networks and research programs to address the current and long-term changes in UV that is applicable to their individual programs. For research studies of UV effects, accurate and reliable measurements of solar UV irradiance are a requirement. Measurements of solar irradiance in the ultraviolet are particularly difficult because of the steep decline in the short wavelength region of the solar spectrum due to the absorption of ozone through the atmosphere. The Central UV Calibration Facility (CUCF) has been tasked with holding Intercomparison campaigns as is necessary to ensure quality measurements between different types of instruments used in UV monitoring and research agencies in the United States especially as instruments are modified and improved. Representative instruments from international programs are invited to ensure comparison between international UV programs.

The primary purpose of these Intercomparisons is to assess the ability of spectroradiometers to accurately measure solar ultraviolet radiation. The North American interagency Intercomparisons of Ultraviolet Spectroradiometers are performed near Boulder, Colorado. The first Intercomparison was held September 19 to 29, 1994; the second June 12 to 23,1995 ; the third June 15 to 25,1996 ; and the fourth Intercomparison was September 17 to 25,1997 . The experimental details and results from these efforts have been described previously $[2,3,4,5]$. The fifth Intercomparison was held June 13 to June 21, 2003 and results are presented here. As with the other Intercomparisons, these synchronized solar irradiance measurements were the most important aspect of the campaign as they allow assessment of the present limits to which irradiance determined by different instruments can be compared. Two sections of this analysis are different compared to previous years. First, this intercomparison employs a tool developed by Gardner et al., [6] to determine the reference spectrum from the participating instruments based on a predefined algorithm termed the arena and reference algorithm. The second is an algorithm used to compensate for the different slitfunctions of the instrument to facilitate comparisons between measurements from the instruments. To account for differences in the slit functions of each of the instruments, the spectral solar irradiance is deconvolved and re-convolved using a 1-nm triangular slit function using a technique developed previously $[7,8]$. The solar irradiance determined from the deconvolution technique is compared to techniques used in previous intercomparisons [9]. This particular year there was a return in an emphasis on a blind comparison of solar irradiance measurements with agencies using their own calibration systems. In the previous campaign, there was an emphasis on new prototype instruments for measuring and monitoring of UV irradiance, which precluded a true "blind" comparison of solar irradiance data because of a lack of current participant calibration systems for several of the instruments. This year synchronized solar scans from each instrument were compared based upon responsivity calibrations performed by the participants as well as performed by the CUCF. Using the CUCF calibrated lamps and field calibration unit provided a common scale for the synchronized measurements of solar irradiance. 


\section{INTERCOMPARISON OVERVIEW}

\subsection{Protocol}

The campaign was designed as a blind intercomparison to include 6 days of solar irradiance measurements from June 16 - June 20, which corresponds to the Day-of-Year (DOY) 167 172. The blind intercomparison included 6 days to maximize the likelihood of clear sky periods. The first several days were reserved for instrumental set-up and calibration by the participants. The protocol was for the participants to synchronize their instruments to start measurements on the half hour from 1200 UTC to 2330 UTC. The synchronized scans started at $290 \mathrm{~nm}$ finishing at $360 \mathrm{~nm}$ and scanned in $0.2 \mathrm{~nm}$ steps every 3 seconds; except for the USDA_U11 instrument which scanned in $0.1 \mathrm{~nm}$ steps in $1.5 \mathrm{~s}$ between each wavelength increment. The scanning time for the synchronized scans from 290 to $360 \mathrm{~nm}$ was $17.5 \mathrm{~min}$. The clock for each instrument was set daily from a common clock synchronized with the satellite Global Positioning System. The ASRC_RSS instrument is a spectrograph and therefore measures all wavelengths simultaneously. A pseudo scan was determined as explained in the instrument description section to compare the ASRC_RSS to other scanning spectroradiometers. Several instruments extended the wavelength scan range to $400 \mathrm{~nm}$ for complete erythema measurements.

Participants were not allowed to exchange data until the completion of the final day of measurements. Solar irradiance measurements using the participants' calibration were submitted the following day. The organizers evaluated the data the evening after submittal to determine if instruments were supplying the data in the correct units and in the correct time zone [UTC]. An exception to the following day rule was allowed for instrument UV-RSS because of the extra work involved in generating a pseudo-scan from the spectrograph and unforeseen algorithm problems for the processing of the pseudo-scan. This precluded the organizers from sharing detailed information about the initial results. The participants were required to calibrate their own instruments using their standard calibration procedures. The participants calibrated and set-up their instruments during the three days prior to the start of the blind comparison days on June $13-15,2003$. In addition, as in previous campaigns, the responsivities of the instruments were determined by the CUCF using NIST traceable $1000 \mathrm{~W}$ Tungsten Halogen lamps calibrated by the CUCF in the horizontal position [10,11]. The responsivities determined by the CUCF were completed using three NIST traceable standard lamps.

\subsection{Participating Agencies and Instruments}

The fifth Intercomparison was coordinated by the Central UV Calibration Facility (CUCF), Earth System Research Laboratory (ESRL), of the National Oceanic and Atmospheric Administration (NOAA). The following agencies and organizations participated: the National UV Monitoring Center (NUVMC) at the University of Georgia which administered the Environmental Protection Agency's (EPA) UV Network from 1995-2005; the National Institute for Water and Atmospheric Research (NIWA) of New Zealand; the Ozone and Water Vapor Group of the Global Monitoring Division (GMD) of the Earth System Research Laboratory (ESRL) of the National Oceanic and Atmospheric Administration (NOAA), Biospherical Instruments which administers the National Science Foundation's (NSF) UV Monitoring Network for Polar Regions, the Smithsonian Environmental Research Center (SERC), the Natural Resource Ecology Laboratory (NREL) of Colorado State University (CSU) which administers the Department of Agriculture's (USDA) UV Monitoring Network [12], the Atmospheric Sciences Research Center (ASRC) of the State University of New 
York (SUNY) which represents the USDA monitoring program, and the Institute of Meteorology and Climatology (IMUK), University of Hanover, Hanover, Germany. A list of agencies and their instruments is given in Table 1. For the remainder of this paper, the instruments will be designated ASRC_RSS, NOAA_NIWA, EPA_BRW, NSF_SUV, USDA_U11 where the acronym conveys the UV Network or agency followed by the instrument type.

Table 1. Participating UV spectroradiometers.

\begin{tabular}{lllll}
\hline \hline Agency & Label & Spectroradiometers & Serial no. & Purpose \\
\hline & & & & \\
ASRC & ASRC_RSS & UV-RSS Spectrograph & 104 & Research, Monitoring \\
EPA & EPA_BRW & Sci-Tec Brewer MKIV & 101 & Research, Monitoring \\
NOAA & NOAA_NIWA & Bentham & UV5 & Research, Monitoring \\
IMUK & IMUK_BEN & Bentham & 5041 & Research, Monitoring \\
NSF & NSF_GUV & BSI GUV 511 & 29236 & Research/Monitoring \\
NSF & NSF_SUV & BSI SUV-150B & NA & Research/Monitoring \\
SERC & SERC & SR-18 and SR-19 & UH,UC,UZ & Monitoring/Materials \\
USDA & USDA_U11 & U111 Spectroradiometer & U111 & Monitoring,Calibration \\
USDA & USDA_MF1 & UV-MFRSR & 232 & Monitoring \\
USDA & USDA_MF2 & UV-MFRSR & 286 & Monitoring \\
& & & & \\
\hline
\end{tabular}

Several different types of spectroradiometers participated in this study that included a total of twelve UV spectroradiometers. These include five scanning spectroradiometers, a spectrograph instrument, and several types of narrow and moderate bandwidth filter radiometers. The results from the six filter radiometers are not presented here. In this paper, the results are presented for five scanning spectroradiometers and one spectrograph. The Brewer spectrophotometer, the USDA U111 spectroradiometer, and earlier versions of the BSI spectroradiometer and RSS Spectrograph have been described in previous Intercomparison papers $[2,3,4,5]$. Several of the instruments have been described in other intercomparison campaigns or cited references $[13,14,15,16,17]$. Table 2 lists the characteristics of each instrument, and brief descriptions are given below.

In summary, the Ultraviolet Rotating Shadowband Spectrograph was developed at the Atmospheric Sciences Research Center (ASRC_RSS) [15,18] and uses an automated shadowband method [19] that allows the instrument to measure quasi-simultaneous diffusehorizontal and total-horizontal spectral irradiance. One Sci-Tec Brewer spectrophotometer (Model MKIV) participated in the intercomparison (EPA_BRW), which utilizes the single monochromator design. The instrument is part of the EPA Brewer Network maintained by the National UV Monitoring Center (NUVMC) of the University of Georgia, Atlanta. The NUVMC maintained 21 sites using Brewer spectrophotometers across the continental United States, Alaska, Hawaii, and the Virgin Islands with 14 stationed in or near National Parks. The UV5 instrument (NOAA_NIWA) is owned by NOAA/ESRL and operated in collaboration with the National Institute of Water and Atmospheric Research (NIWA), New Zealand, who developed the instrument system, including data logging and analysis software. This instrument operates in the ultraviolet-visible with a scanning double monochromator. The instrument is typically located on the roof of the NOAA ESRL building in Boulder, CO. The Biospherical Instruments SUV-150B ultraviolet-visible spectroradiometer system (NSF_SUV) is based on a scanning double-monochromator that is used in the NSF UV Arctic Program [14, 20]. International participation was represented by a scanning double monochromator spectroradiometer from the Institute of Meteorology and Climatology, 
University of Hanover (IMUK_BEN). [21]. A description of this spectroradiometer is given in Wuttke et al. [17]. The U Series Ultraviolet spectroradiometers were designed and built by the Atmospheric Science Research Center and Instruments SA for use in the USDA UV Network (USDA_U11) and this instrument resides permanently at the Table Mountain Test. The design and data processing of this instrument are described further in several references $[5,16,22]$.

DOY 167,2003
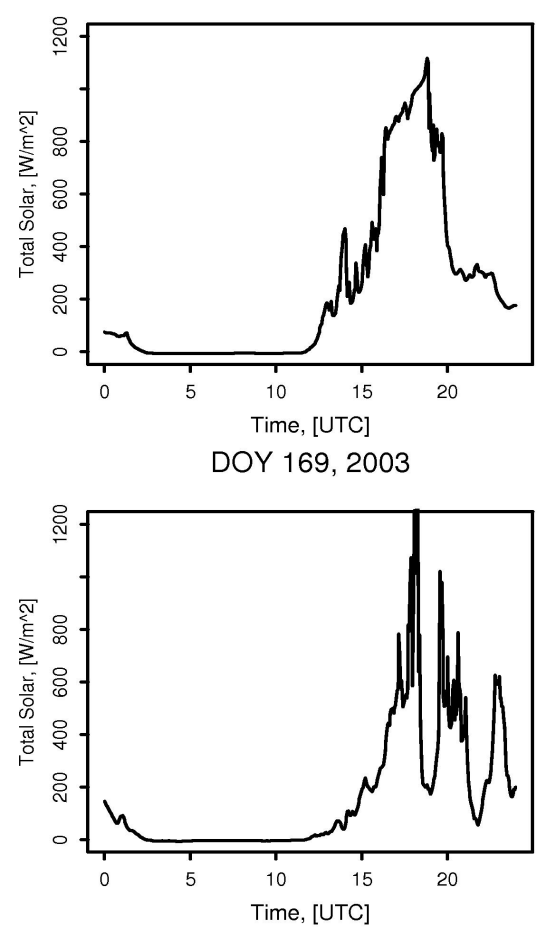

DOY 171,2003

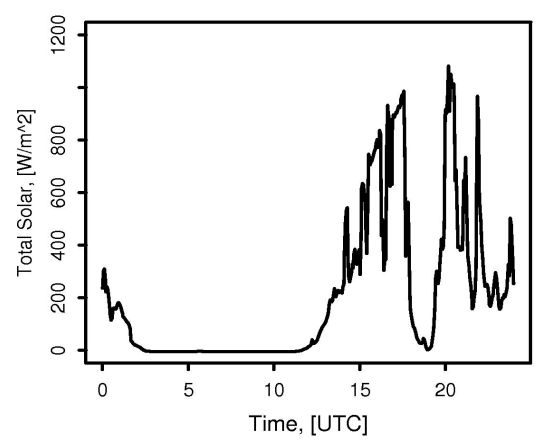

DOY 168,2003
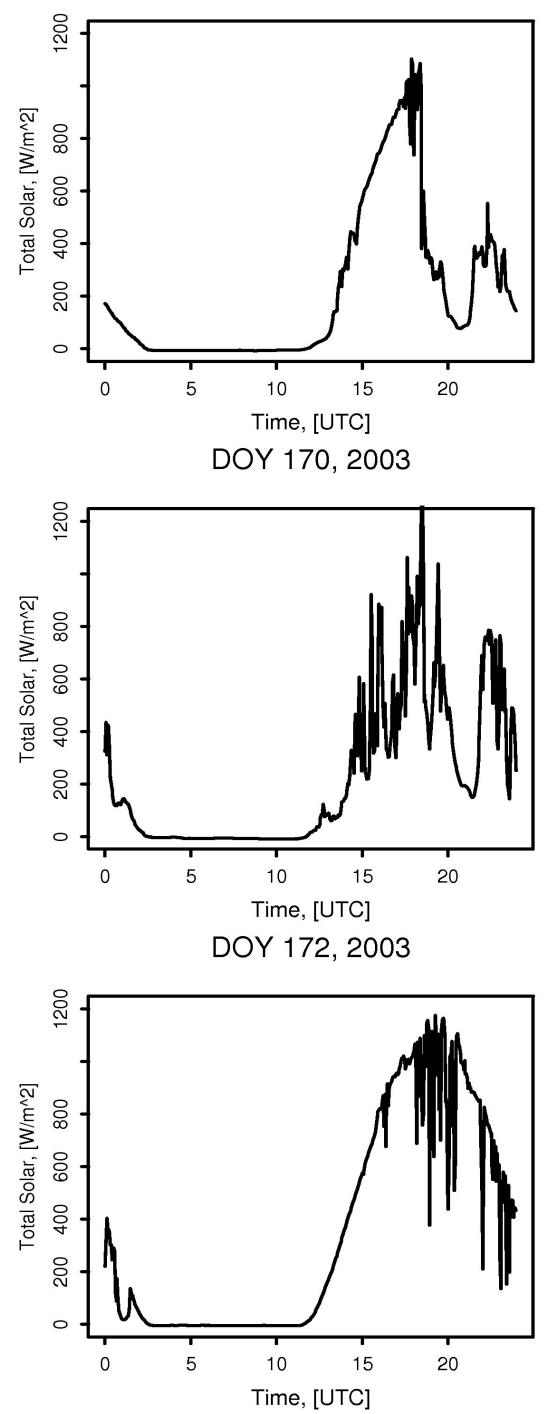

Fig. 1. Total horizontal irradiance as a function of time [UTC] from a solar pyranometer on the days indicated in the panels. 
Table 2. Spectroradiometer specifications.

\begin{tabular}{|c|c|c|c|c|c|c|}
\hline Participant/Network & ASRC_RSS & NOAA_NIWA & EPA_BRW & IMUK_BEN & NSF_SUV & USDA_U11 \\
\hline Spectroradiometer Model & UVRSS & Bentham DTM300 & Brewer MKIV & Bentham DTM 300 & SUV_150B & U1000 \\
\hline Manufacturer & ASRC & NIWA & SCI-TEC & Bentham Instruments & BSI & ASRC + Inst. SA \\
\hline Serial Number & $104 \mathrm{~S}$ & UV5 & $93-101$ & 5041 & 11003 & Prototype \\
\hline Scanning / Spectrograph & Spectrograph & Scanning & Scanning & Scanning & Scanning & Scanning \\
\hline $\begin{array}{l}\text { Diffraction Grating (DG) } \\
\text { /Prism }\end{array}$ & 2 Prisms & $\begin{array}{l}\text { Grating: Czerny Turner } \\
\text { Double } \\
\text { Monochromator }\end{array}$ & $\begin{array}{l}\text { Grating: Modified Ebert } \\
\text { Single Monochromator }\end{array}$ & $\begin{array}{l}\text { Grating: Czerny-Turner } \\
\text { Double- Monochromator }\end{array}$ & $\begin{array}{l}\text { Grating: Czerny-Turner } \\
\text { Double Monochromator }\end{array}$ & $\begin{array}{l}\text { Grating: Czerny Turner } \\
\text { Double Monochromator }\end{array}$ \\
\hline Detector & $\begin{array}{l}\text { CCD Open } \\
\text { Electrode }\end{array}$ & $\begin{array}{c}\text { PMT, Hamamatsu } \\
\text { R1527 }\end{array}$ & $\begin{array}{l}\text { PMT (low noise EMI } \\
\text { 9789QA) }\end{array}$ & PMT DH 10-te & $\begin{array}{l}\text { PMT Hammamatsu R2371P } \\
(\text { HC120-03) }\end{array}$ & $\begin{array}{l}\text { PMT Hamamatsu R2371- } \\
02\end{array}$ \\
\hline Nominal Bandwidth & $0.3-0.6 \mathrm{~nm}$ & $0.8 \mathrm{~nm}$ & $0.6 \mathrm{~nm}$ & $0.5 \mathrm{~nm}$ & $0.7 \mathrm{~nm}$ & $0.1 \mathrm{~nm}$ \\
\hline Range [nm] & $295-385$ & $285-450$ & $286.5-363$ & $290-500$ & $250-700$ & $290-410$ \\
\hline Diffuser Material & Teflon $(8.2 \mathrm{~mm})$ & PTFE (52.6 mm) & $\begin{array}{c}\text { Teflon }(3.5 \mathrm{~cm}) \\
\text { Quartz dome }(5 \mathrm{~cm})\end{array}$ & Teflon $(2.5 \mathrm{~cm})$ & Teflon over Quartz $(25 \mathrm{~mm})$ & PTFE $(25 \mathrm{~mm})$ \\
\hline Weatherproof & Yes & Yes & Yes & Yes & Yes (Collector only) & Yes \\
\hline $\begin{array}{l}\text { Temperature: Optics } \\
\text { Temperature: Detector }\end{array}$ & Yes & $\begin{array}{l}\text { Yes } \\
\text { Yes }\end{array}$ & Software corrected & $\begin{array}{l}\text { No } \\
\text { Yes }\end{array}$ & $\begin{array}{l}\text { Yes } \\
\text { Yes }\end{array}$ & $\begin{array}{l}\text { Yes } \\
\text { Yes }\end{array}$ \\
\hline Filter & Hoya U340 3mm & None & $\begin{aligned} & <325 \mathrm{~nm} 0.5 \mathrm{ndf} \\
& +\mathrm{NiSO} 4+\mathrm{UG} 11 \\
> & 325 \mathrm{~nm} \text { ndf +UG11 }\end{aligned}$ & $\begin{array}{c}\lambda<400 \mathrm{~nm}: \text { no filter } \\
\lambda>400 \mathrm{~nm}: \text { OS } 400\end{array}$ & None & None \\
\hline $\begin{array}{l}\text { Angular Response } \\
\text { Corrected }\end{array}$ & Yes & No & Yes & No & Yes & No \\
\hline Dark Current removed & Yes & Yes & Yes & Yes & Yes & Yes \\
\hline Stray Light Removed & Yes & Yes & Yes & No & Yes & No \\
\hline $\begin{array}{l}\text { Wavelength Registration } \\
\text { [nm] }\end{array}$ & Fraunhofer Lines & $\begin{array}{c}\text { Fraunhofer Lines } \\
\text { Hg Line }\end{array}$ & $\begin{array}{l}302.15 \mathrm{~nm} \\
\text { Hg Line }\end{array}$ & Fraunhofer Lines & Fraunhofer Lines & $\begin{array}{l}296.728 \\
\text { Hg Line }\end{array}$ \\
\hline $\begin{array}{l}\text { Primary Lamp }[\mathrm{W}]^{*} \\
\text { Secondary Lamp }[\mathrm{W}]\end{array}$ & $\begin{array}{c}1000 \mathrm{~W} \\
250 \mathrm{~W} \text { external }\end{array}$ & $\begin{array}{c}1000 \mathrm{~W} \\
45 \mathrm{~W} \text { internal }\end{array}$ & $\begin{array}{c}1000 \mathrm{~W} \\
50 \mathrm{~W} \text { external }\end{array}$ & $\begin{array}{c}1000 \mathrm{~W} \\
100 \mathrm{~W} \text { external }\end{array}$ & $\begin{array}{l}\text { 1000W FEL QTH } \\
200 \mathrm{~W} \text { and } 45 \mathrm{~W} \text { QTH }\end{array}$ & $\begin{array}{c}1000 \mathrm{~W} \\
20 \mathrm{~W} \text { internal }\end{array}$ \\
\hline
\end{tabular}




\subsection{Site Description and Atmospheric Conditions}

The site of the Intercomparison was the Table Mountain Test Facility (TMTF) located at latitude $40.125^{\circ} \mathrm{N}$, longitude $105.237^{\circ} \mathrm{W}$, at an elevation of $1689 \mathrm{~m}$. The site is a plateau approximately $12.9 \mathrm{~km}$ north of Boulder, Colorado and $5.6 \mathrm{~km}$ east of the Rocky Mountains with a fairly clear view to the northern, eastern, and southern horizon. The highest, and only major, obstruction to the horizon was a peak $5.6 \mathrm{~km}$ due west of the site that extends $5.1^{\circ}$ above the horizon.

The availability of ancillary instrumentation measuring atmospheric conditions is useful for correlating the measured solar ultraviolet irradiance with changing conditions such as cloud cover. Results from one solar pyranometer are shown in Fig. 1 where the irradiance is plotted as a function of time for each day. This solar pyranometer measures total horizontal irradiance from $280 \mathrm{~nm}$ to $3000 \mathrm{~nm}$. The temperature, relative humidity, barometric pressure, and wind speed and direction were recorded at the site. The temperature ranged on average from $14{ }^{\circ} \mathrm{C}$ in the early morning to nearly $24{ }^{\circ} \mathrm{C}$ in the late afternoon. The relative humidity varied between $20 \%$ - 95\% reaching highs during stormy periods. The barometric pressure ranged from 820 mbar to a maximum of 838 mbar. Weather conditions (DOY $167-172$ ) were generally partly-cloudy to overcast with periods of heavy rain. During the first day of the Intercomparison the weather was moderately favorable with periods of stable sky. Later in the week, there was increasing cloudiness with drizzle and heavy rain predominately in the afternoon (DOY 168 - 171). The weather was best during the last day of the synchronized scans providing an almost cloud-free period for the morning of DOY 172. On the night of 171 , the weather began to clear, stayed clear for the following morning until the afternoon when broken clouds moved in over the instruments. The weather was completely clear and characterized by blue sky for the final day when instruments were breaking down, undergoing their final responsivity measurements by the CUCF, or involved in extended scan comparisons [17]. DOY 167 and 172 are used for the comparison of solar irradiance between instruments in the following sections. DOY 172 is chosen because it provides a cloud-free period in the morning and DOY 167 is chosen as a representative day that was not completely clear of clouds but also did not exhibit torrential rain. Please note the times given in this paper are in Universal Coordinated Time (UTC), $6 \mathrm{~h}$ ahead of Mountain Daylight Time, the local time.

\section{INSTRUMENT CHARACTERIZATIONS}

\subsection{Introduction}

Uncertainties in the solar irradiance measurements arise primarily from the radiometric calibration (i.e. spectral responsivity), angular response error and method of correction, straylight rejection, wavelength uncertainties, and the stability of the instrument both temporally and under varying atmospheric conditions. During this comparison there was not as much emphasis on instrument characterizations on site at the intercomparison as in previous years, e.g. slit-function, stray-light rejection, and wavelength uncertainty analyses. The main reason is that most instruments have been fully characterized in previous studies and/or have participated previously in North American Intercomparisons where instrument characterization occurred (i.e. ASRC_RSS, EPA_BRW, USDA_U11) [2,3,4,5]. Instruments that have not participated in previous North American Intercomparisons (NSF_SUV, IMUK_BEN, NOAA_NIWA) have been characterized fully elsewhere. However, the wavelength accuracy was checked using an algorithm developed by H. Slaper and results are 
presented in this section [7,8]. The angular response was not measured at the Intercomparison, but the magnitude of the correction to the solar irradiance due to a non-ideal angular response is given based on previous measurements by the participants at their home facilities. The spectral responsivity determined by the participants and the CUCF are presented here. The stability of the CUCF calibration lamps is presented in section 4 .

Table 3. Summary of stray-light, wavelength accuracy and bandwidth.

\begin{tabular}{|c|c|c|c|c|c|c|}
\hline & ASRC_RSS & EPA_BRW & IMUK_BEN & NOAA_NIW & NSF_SUV & USDA_U11 \\
\hline Stray-Light* & $2 \times 10^{-6}$ & $3 \times 10^{-5}$ & $\begin{array}{c}<10^{-6} \\
\text { Noise limited }\end{array}$ & $\begin{array}{c}<10^{-6} \\
\text { Noise limited }\end{array}$ & $<10^{-6}$ & $\begin{array}{c}<10^{-10} \\
\text { Noise limited }\end{array}$ \\
\hline \multicolumn{7}{|l|}{ Wavelength* } \\
\hline Accuracy & \pm 0.05 & \pm 0.05 & $< \pm 0.05$ & $< \pm 0.04$ & $< \pm 0.04$ & \pm 0.02 \\
\hline Precision & \pm 0.02 & \pm 0.02 & $< \pm 0.03$ & $< \pm 0.02$ & $< \pm 0.02$ & \pm 0.01 \\
\hline $\begin{array}{c}\text { Nominal } \\
\text { Bandwidth } \\
{[\mathrm{nm}]}\end{array}$ & 0.5 & 0.6 & 0.54 & 0.75 & 0.7 & 0.1 \\
\hline $\begin{array}{l}\text { SHICrivm } \\
\text { shift [nm]** }\end{array}$ & NS & -0.03 & 0.00 & 0.03 & -0.04 & NS \\
\hline $\begin{array}{l}\text { DOY } 167 \\
\text { DOY } 172\end{array}$ & NS & -0.03 & 0.01 & 0.03 & -0.04 & NS \\
\hline
\end{tabular}

* Measurements from participants or previous intercomparisons.

** Measurements from SHICrivm code at $305 \mathrm{~nm}$

\subsection{Wavelength uncertainty}

Wavelength drive instabilities can be a significant source of error in the measurement of spectral solar irradiance. Wavelength shifts cause errors in the solar irradiance as a function of wavelength, solar zenith angle, and total ozone, where errors are the largest at short wavelength, larger total ozone and solar zenith angle. For erythemally weighted solar irradiance, a wavelength shift of $0.1 \mathrm{~nm}$ can cause errors in the solar irradiance of approximately $1-2 \%$. For detailed curves of the effect of a $0.1 \mathrm{~nm}$ wavelength shift on spectral solar irradiance and weighted solar irradiance see Bernhard et al. [23]. Wavelength shifts in the solar irradiance measurements have been calculated using the SHICrivm algorithm. This code is used for the standardization of spectra for the comparison of spectral solar irradiance in section 6 , but has the added advantage of checking the instruments' wavelength accuracy using the sun's Fraunhofer structure. The wavelength uncertainty for several of the instruments has been determined in previous intercomparisons using singlet lines from $\mathrm{Cd}$ and $\mathrm{Zn}$ lamps that were not used for the instruments' routine wavelength calibration or registration (e.g. EPA_BRW, USDA_U11, NSF_SUV, ASRC_RSS). Since most instruments had participated in previous North American intercomparisons or the participants had previously characterized their instruments, this check was not performed this particular year. Where available from previous studies, the wavelength precision and accuracy is summarized in Table 3. The wavelength registration of the instruments during the intercomparison is performed either or both by using emission lines from an Hg lamp [24] and/or using the solar Fraunhofer structure [see Table 2].

The reported wavelength accuracy capable using the SHICrivm method is $0.02 \mathrm{~nm}$ with a reproducibility of $0.01 \mathrm{~nm}$ across the wavelength range 300-400 $\mathrm{nm}[7,8]$. The wavelength accuracy depends on the wavelength accuracy of the extraterrestrial spectrum used in the analysis. This is problematic for instruments that have a reported accuracy better than 0.02 
$\mathrm{nm}$ such as the USDA_U11 instrument. The SHICrivm algorithm applies the wavelength shifts to the deconvolved solar irradiance data compared in section 6.3. A summary of the wavelength shifts applied to the solar irradiance measurements from DOY 167 and 172 are given in Table 3. The algorithm estimates the significance of the wavelength shift. If the fit is not significant within $1 \%$, then the wavelength shifts are not applied to the solar irradiance data; the table entry indicates a NS for not significant, which occurs for both USDA_U11 and ASRC_RSS. In section 6, the solar irradiance is also compared using the band-width standardization methods at the previous four North American Intercomparisons and for this method there is no wavelength shift applied to any of the solar irradiance measurements from any of the instruments.

\subsection{Angular Response}

Solar irradiance is defined by the amount of power reaching a flat horizontal surface per unit area per wavelength. The flux incident on a horizontal surface ideally varies with the cosine of the incident angle, but in reality deviates from this ideal response because of imperfect input optics. Full characterization of the angular response of the instrument is determined by measuring the signal from a source as a function of the incident zenith and azimuth angle for each wavelength. Typically, angular response measurements are carried out either in the laboratory using a lamp as a source or in the field using the sun as the source. Newer spectroradiometers have designed their diffusers to minimize the deviations from an ideal angular response (e.g. ASRC_RSS, IMUK_BEN, NOAA_NIWA, NSF_SUV, USDA_U11); however older instruments can have significant angular response errors (e.g. EPA_BRW). Fig. 2 gives the angular response for the five scanning spectroradiometers and the spectrograph relative to the ideal cosine response. The angular response for the IMUK_BEN instrument was measured at 320 and $400 \mathrm{~nm}$, and the figure is the average of the two measurements with deviations of less than $0.5 \%$. The angular response of the NSF_SUF instrument was measured at $320,350,400,500$, and $600 \mathrm{~nm}$ for azimuthal angles of $\overline{0}, 90$, 180, and 270 degrees. The data provided and plotted in Fig. 2 is the average of the individual measurements. No significant azimuthal or wavelength dependence of the angular response was observed. The ASRC_RSS angular response measurements were measured at several wavelengths and in two planes with no significant wavelength or azimuthal dependence. Two planes were averaged to give the measurements shown in Fig. 2.

Correction of the solar irradiance for the deviations from an ideal angular response can be difficult because in addition to the characterization of the angular response shown in Fig. 2 , the correction requires knowledge of the sky radiance and partitioning of solar irradiance into diffuse and direct components. Table 4 indicates whether the solar irradiance measurements for the six spectroradiometers have been corrected for the non-ideal angular response and gives the approximate range of the correction across solar zenith angles whether or not the correction was applied. The solar irradiance measurements from the NOAA_NIWA instrument have not been corrected for angular response error during the intercomparison, however in routine analysis the correction was between $1-2 \%$. The solar irradiance measurements from the ASRC_RSS instrument has been corrected for the angular response error and uses the instrument's rotating shadow-band feature to retrieve the diffuse and direct solar irradiance and uses the measured and values for the angular response corrections. 


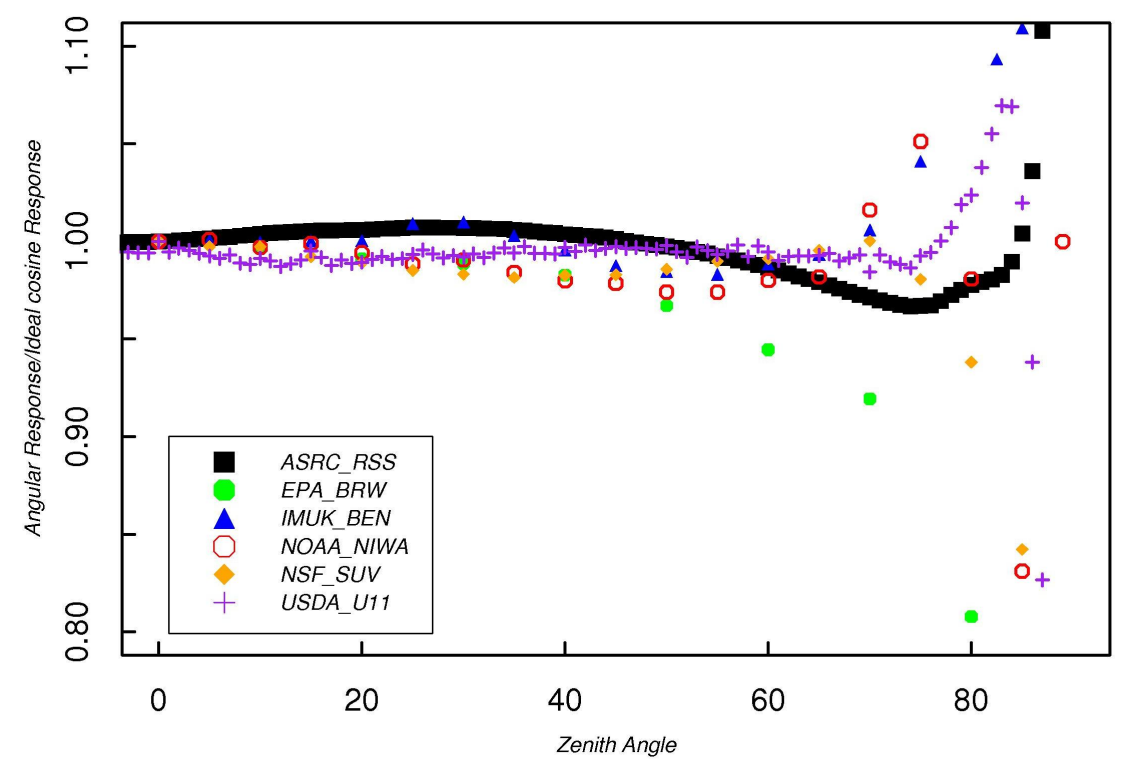

Fig. 3. Angular response relative to the ideal cosine response for each of the instruments.

Table 4. Angular response corrections to solar irradiance measurements.

\begin{tabular}{lll}
\hline Instrument & Cosine-corrected & Approx. Correction \\
\hline ASRC_RSS & Yes* & $0.4-1.4 \%$ \\
EPA_BRW & Yes & $0.8-7 \%$ \\
IMUK_BEN & No & Not Available \\
NOAA_NIWA & No & $1-2 \%$ \\
NSF_SUV & Yes & $0.8-1.3 \%$ \\
USDA_U11 & No & $0.3-0.8 \%$ \\
\hline
\end{tabular}

* Measurements of diffuse and direct irradiances used in calculation of correction.

\subsection{Spectral Irradiance Responsivity}

\subsubsection{Introduction}

The spectral irradiance responsivities or simply responsivity of the instruments were determined by the participants using their own calibration systems and again by the CUCF using the NOAA/CUCF standard lamps and field calibration unit [25]. Several of the participating agencies use calibration systems that are linked to the CUCF either because the agency uses the CUCF personnel and equipment to calibrate their instruments or the agency purchases horizontally calibrated $1000 \mathrm{~W}$ Tungsten lamps from the CUCF. Therefore, as in previous campaigns, the responsivity of all the instruments are measured using CUCF calibrated lamps to eliminate differences between solar irradiance measurements from the instruments due to the source of the calibration lamps and due to different field calibration units [25]. This avoids the potential bias or grouping of solar irradiance measurements that may occur if only a few instruments' calibration systems are linked to the same source. 
Previous Intercomparisons demonstrated that moving the instruments after calibration caused measurable changes in the responsivity; therefore, the participants were encouraged to calibrate their instrument on-site outdoors on the concrete pads where the instrument remained for the entirety of the Intercomparison $[3,4]$. The participants calibrated their instruments prior to the start of the Intercomparison during the set-up period. The CUCF standard lamps were operated in the field calibration unit whose performance was demonstrated at the previous Intercomparisons [25]. The CUCF calibrated instruments either the week prior to the start of the Intercomparison or the week after the end of the blind Intercomparison on DOY 172, 2003. Below is a description of the experimental procedure used for the responsivity measurements from the CUCF.
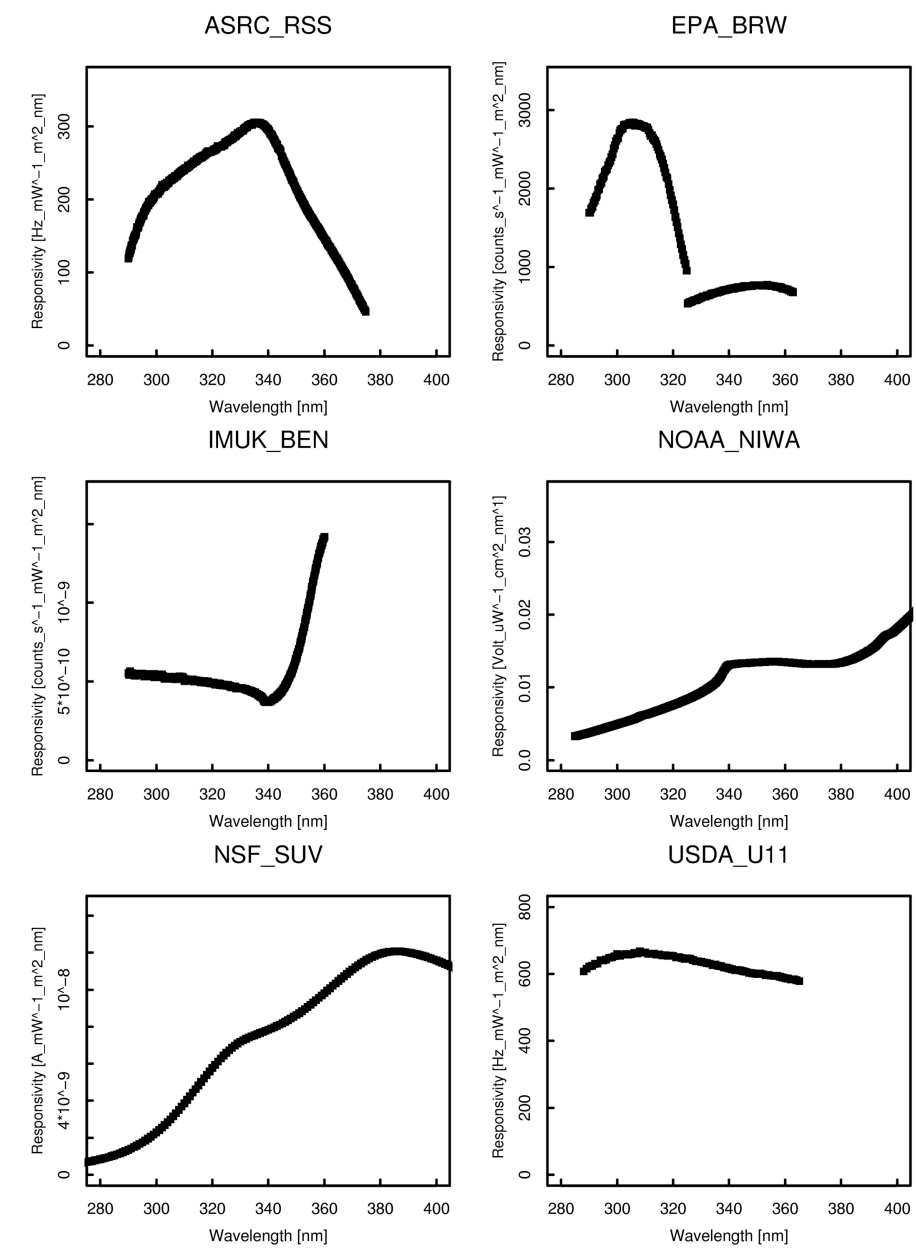

Fig. 3. Responsivity as a function of wavelength for each instrument indicated in the panels.

\subsubsection{Experimental Procedure}

The field calibrator was developed in collaboration with NIST and field tested at a previous Intercomparison [3]. Details of the CUCF field calibration unit are given in a separate paper [25]. Briefly, the field calibration unit consists of three circular baffles, $45 \mathrm{~cm}$ in diameter and separated by $15 \mathrm{~cm}$, with a mount for a horizontal lamp on the top baffle. The lamp is 
isolated from the surroundings by shrouding around the baffles and a light trap above the lamp. The unit mounts on an interface plate, which is the key to the utility of the field calibration unit. Each instrument has an interface plate specifically designed to fit around the diffuser and rest on top of the instrument. The interface plate also sets the distance from the diffuser to the lamp at $50.0 \mathrm{~cm}$ by using spacers machined to the appropriate height. The lamp mount on the field calibration unit was adjusted once to center the lamp $50.0 \mathrm{~cm}$ above the diffuser.

The spectral irradiance of the $1000 \mathrm{~W}$ FEL-type Tungsten halogen standard lamp was determined by CUCF in the horizontal position using a method similar to the one described previously and the stability is presented in section 4 [25]. The responsivity of each instrument was determined with the calibrated lamps mounted horizontally in the field calibration unit. For all determinations of responsivity using a CUCF lamp, spectral scans were performed with a $3.5 \mathrm{~cm}$ wide shutter halfway between the lamp and the diffuser to measure the scattered light signal, and without the shutter to measure the total signal.

The responsivity is determined by dividing the net-signal from the spectral scans by the lamp irradiance. For the CUCF standard lamps, the net-signal is the direct signal, given by the difference between the total signal and the scattered light signal. The CUCF standard lamps were calibrated from $250 \mathrm{~nm}$ to $400 \mathrm{~nm}$ in $10 \mathrm{~nm}$ steps and again at $450 \mathrm{~nm}$, which covers the wavelength range measured during this Intercomparison. Components of uncertainty arise from the standard lamp (spectral irradiance, size of diffuser, goniometric distribution, and current stability), the alignment of the lamp, and the instrument (wavelength and signal). The greatest systematic component is the irradiance of the standard lamp, while the greatest random component is the measured signal. A schedule of the spectral scans of standard lamps is given in Table 5, along with the corresponding instrument temperatures if available. In the table, the lamp names indicated in bold are used for the CUCF responsivity for solar irradiance measurements in section 6. If more than one lamp is highlighted, then the average of the lamps is used. Figure 3 presents an example of the spectral responsivity for each of the spectroradiometers.

Table 5. Spectral Responsivity Measurements.

\begin{tabular}{|c|c|c|c|c|}
\hline Instrument & Day & Calibration & Lamp & {$\left[{ }^{\circ} \mathbf{C}\right]$} \\
\hline \multirow{2}{*}{ EPA_BRW } & 164 & Participant & GS977_GS978 & 23.5 \\
\hline & 175 & CUCF & Н-025,Н-027,H-030 & 23.2 \\
\hline \multirow{2}{*}{ ASRC_RSS } & 167 & Participant & Н-015,Н-024,Н-028 & NA \\
\hline & 174 & CUCF & H-025,H-027,H-030 & NA \\
\hline \multirow{2}{*}{ IMUK_BEN } & $166-172$ & Participant & 59741 & NA \\
\hline & 166 & CUCF & H-025,H-027,H-030 & NA \\
\hline \multirow{2}{*}{ NOAA_BEN } & 155 & Participant & H-015,H-024,H-028 & 29.1 \\
\hline & 170 & CUCF & H-025,Н-027,Н-030 & 29.0 \\
\hline \multirow{3}{*}{ NSF_SUV } & 149 & Participant & 200W028 & NA \\
\hline & 167 and 174 & Participant & M-763 & NA \\
\hline & 174 & CUCF & H-025,Н-027,Н-030 & NA \\
\hline \multirow{2}{*}{ USDA_U11 } & 156 & Participant & Н-015,Н-024,Н-028 & NA \\
\hline & 176 & CUCF & H-025, H-027,H-030 & NA \\
\hline
\end{tabular}


Lamp H-025
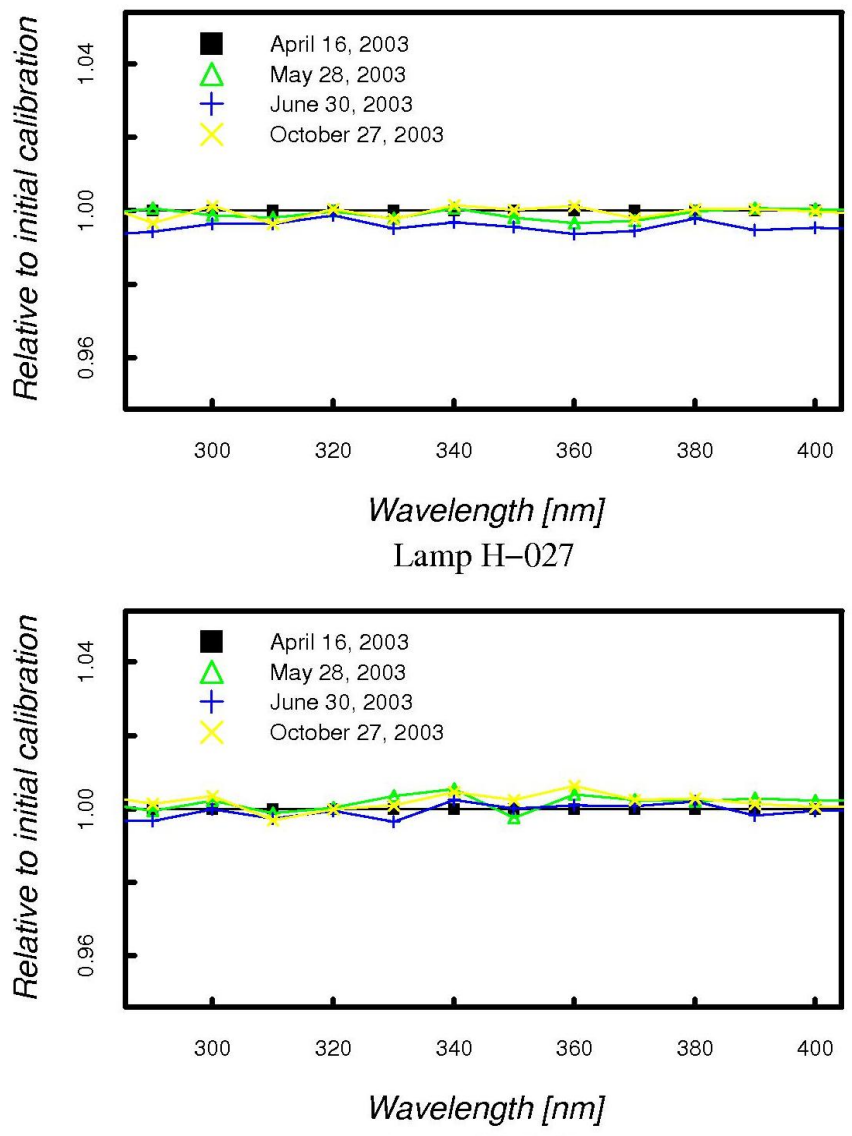

Lamp H-030

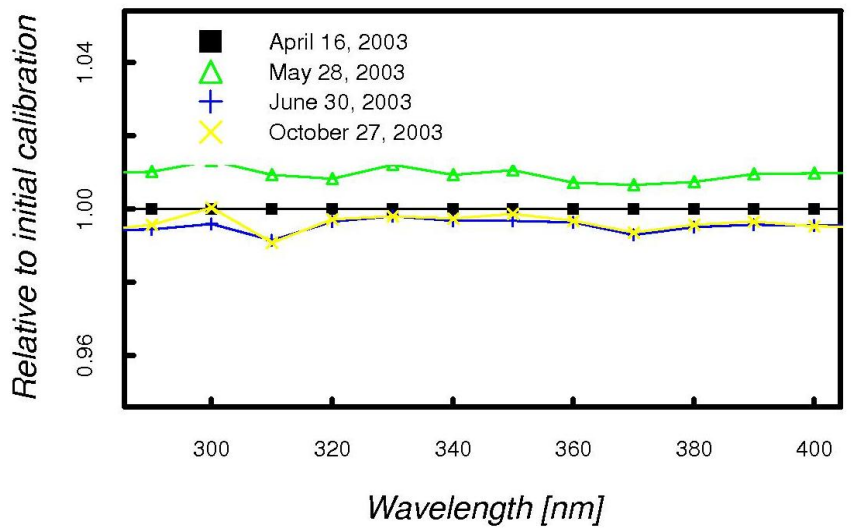

Fig. 4. Stability check of the irradiance scale of the CUCF standard lamps. The ratio of the CUCF irradiance scale determined on two dates prior to the start of the intercomparison and two dates after the end of the intercomparison. The three lamps are indicated in the headers and the calibration dates in the legend. 


\section{CUCF LAMP IRRADIANCE SCALE}

\subsection{Introduction}

As described above, the responsivities of the instruments are determined by the CUCF using CUCF calibrated lamps and the CUCF field calibration unit to eliminate differences between solar irradiance measurements from the instruments due to the calibration source and the field calibration unit. The $1000 \mathrm{~W}$ Tungsten halogen lamps used for the responsivity determination on each of the spectral instruments are calibrated by the CUCF before and after the blind intercomparison period and are traceable to NIST. The irradiance scales of the three lamps are determined four times across the year. Two measurements of the irradiance scale for each lamp occurred before the intercomparison (DOY 106 and DOY 148), and two measurements occurred after the intercomparison (DOY 181 and 300).

The calibration system for generating horizontally calibrated lamps was developed in collaboration with the Optics Division of the National Institute for Science and Technology, NIST $[10,25]$. The stability of horizontally and vertically calibrated lamps was described in a previous study [11]. In this section, the irradiance scales of the lamps used for the responsivity determination of the instruments is compared before the start and after the end of the Intercomparison against the NIST primaries. In addition, the responsivities determined by the U111 Spectroradiometer for the three lamps are compared and the differences are shown.

\subsection{Results and Discussion}

Three CUCF secondary working standards were used to calibrate all the spectral instruments at the Intercomparison, H-025, H-027, H-030. The use of three lamps improves the ability to detect if a given lamp has gone awry in its irradiance scale. Vertically calibrated $1000 \mathrm{~W}$ Tungsten halogen lamps are purchased from NIST. Currently, the CUCF owns six verticallycalibrated NIST primaries. The CUCF transfers the irradiance scale from the verticallycalibrated NIST primaries to the horizontally calibrated CUCF secondary standards that are then used as the working standards for this Intercomparison. The CUCF has its own detailed screening and seasoning process for lamps before a lamp can be identified as a CUCF working standard [11]. The irradiance scale transfer system is able to detect changes in the lamp to better than $0.5 \%$.

The irradiance scales of the three lamps used in the spectral responsivity determinations are determined using the NIST primaries prior to the start of the Intercomparison on DOY 148, 2003 and again after the end of the Intercomparison on DOY 181, 2003. If changes in the irradiance scale between scale transfers exceed the specifications for stability set by the CUCF of approximately $1 \%$ between transfers in the spectral region of interest $290-400 \mathrm{~nm}$, then the lamp is rejected and not used in the analysis of the Intercomparison data set. Figure 4 gives the percent change of the irradiance scale for the three lamps (H-025, H-027, H-030) from four calibration transfers from the NIST primaries in 2003. DOY 148 to 181 spans before to after the blind Intercomparison period. The plot indicates the stability of the lamps across the year and across the Intercomparison period. Lamps $\mathrm{H}-025$ and $\mathrm{H}-027$ are fairly stable within $0.5 \%$ from April to October in the spectral range of $290-400 \mathrm{~nm}$. However, lamp H-030 shows an increase in the irradiance scale of $0.9 \%$ from April to May and then decreases from May to October. The erratic behavior could be an early indicator that this lamp will not be a good working standard. The CUCF requested that lamp H-030 be removed from the line-up and lamps $\mathrm{H}-025$ and $\mathrm{H}-027$ be used for the responsivity determination of each instrument. However, the owners of instruments EPA_BRW, ASRC_RSS, and USDA_U11 decided the differences between responsivity measurements 
were minor and preferred the statistical advantage of averaging the responsivities of the three lamps for the determination of the solar irradiance using CUCF lamps.

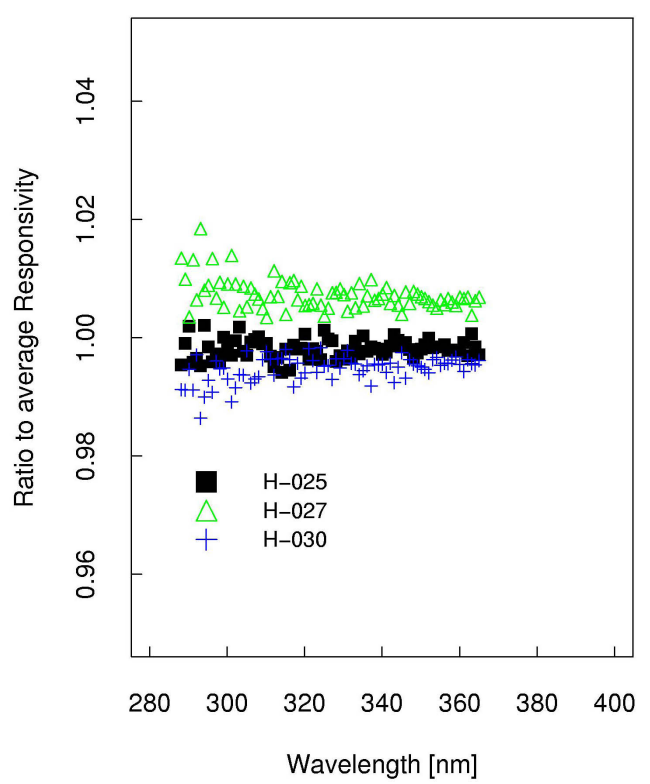

Fig. 5. The ratio of the responsivity of the USDA_U11 spectroradiometer determined with three different CUCF standard lamps indicated in the legend to the average responsivity from all three lamps.

The differences in the responsivities of the U111 spectroradiometer determined with the three CUCF lamps, i.e. H-025, H-027, H-030, on DOY 176 is shown in Fig. 5 DOY 176 is four days after the end of the blind intercomparison days. The three responsivities are determined within 2 hours and the external temperature varied by 0.15 degrees Celsius. Lamp $\mathrm{H}-025$ and $\mathrm{H}-030$ agree within $0.4 \%$; however lamp H- 027 is shown to give a responsivity approximately $1 \%$ high with respect to the other two lamps. In section 6 , the solar irradiance comparisons using the CUCF calibrations use lamp H-025 for the responsivity, except for the three instruments noted above that used an average from the three lamps. The responsivity changes could be due to several issues including temperature dependence or degradation of the optical components, diffuser changes due to temperature, or surface contamination. The relative standard uncertainties in the spectral irradiance of the lamps propagated from the NIST standard lamps to secondary standards and transferred to working horizontal lamps are $1.6 \%$ to $0.9 \%$ from $280-400 \mathrm{~nm}[25]$.

\section{REFERENCE AND ARENA ALGORITHM}

For the comparison of the synchronized solar irradiance scans, a reference spectrum needs to be chosen. Ideally, the true solar spectrum should be the reference spectrum but there is no defined "true" spectrum. There are a number of possible methods for determining the reference spectrum such as using a modeled spectrum, measurements from a single or multiple instruments based on the instrument's characteristics (e.g. stray light rejection), average of the measurements from all participating instruments, or selected from 
measurements based on instrument performance during the campaign. In previous Intercomparisons, the reference spectrum was chosen as the average of measurements from the participating instruments. This has worked in the past, perhaps fortuitously, in that most instruments operated throughout the day and performed well. However, what happens if an instrument performs poorly and deviates significantly from the average or does not operate at desired times of the day? Because there is a perceived advantage to being included in the reference in that it indicates a reliable and accurate instrument, it is preferable to have a method for determining the instruments to be included in the reference spectrum that is unbiased. In the organizational meeting prior to the start of the blind Intercomparison, the participants agreed to use a method developed by Gardiner et al. [6] to determine the reference spectrum.

A group of instruments to be used for the reference spectrum is chosen for each day (i.e. each day has one set of instruments used in the reference spectrum). It is advantageous to have one set of instruments for the entire day because it allows for easy comparison of the solar irradiance as a function of solar zenith angle. There are two parts for determining instruments to be included in the reference spectrum. The first is the Arena Algorithm which considers whether an instrument measures at desired times through out the day, regardless of how an instrument's solar irradiance measurements compare to the other measurements. The reference algorithm considers the instruments based on how the results compare at select observational times and for given wavelength bands. Using the Arena Algorithm and Reference Algorithm as defined can be very cumbersome and time consuming but has the necessary advantage of maintaining objectivity in the determination of the reference spectrum. An overview of the arena and reference algorithm as it pertains to the results of this Intercomparison are given in a NOAA Technical Memorandum [26], where an explanation of the formulas and procedures can be found in the paper by Gardiner et al. [6]. The reference and arena set of instruments have been determined for DOY 167 and 172, 2003; which are the two days used in the solar irradiance comparisons given in section 6 . These two days are chosen from six days of the blind Intercomparison because these days had the most favorable atmospheric conditions as described in section 2.4.

\subsection{Arena Algorithm}

In summary, the goal is to find a reference set that allows most of the instruments to be included under a broad range of conditions and times of the day. Hence, the arena algorithm is designed to make a compromise between maximizing the number of instruments in the arena while maximizing the representative observations throughout key times of the day, e.g. it is desirable to have representative measurements around noon, morning and afternoon. The arena algorithm considers different possible candidate arenas and evaluates them on a point basis. The diurnal observations are divided into seven time bands in the same manner as the original study [6], where the bands cover solar noon, low and moderate solar zenith angles. The instruments are required to have points greater than zero in the mandatory bands otherwise the instrument is excluded from the arena. .

On DOY 167, all six spectroradiometers participated. Instrument USDA_U11 is immediately excluded because it has no observations in the morning mandatory time bands. Possible candidate arenas are considered by throwing out missing observation times and hence points or excluding the instrument. The largest arena score occurred with the candidate arena that excluded time 19.5 UTC. The arena of instruments to be evaluated for the reference algorithm in section 6.3 for DOY 167 includes EPA_BRW, IMUK_BEN, NSF_SUV, NOAA_NIWA, ASRC_RSS.

For DOY 172, all six spectroradiometers participated because all have observations in mandatory time bands. The EPA_BRW instrument is missing observations at key times and 
excluding this instrument and observations times 14.5 and 20.5 UTC results in the maximum arena score from the possible candidate arenas. The arena of instruments to be evaluated for the reference algorithm in section 6.3 for DOY 172 includes USDA_U11, IMUK_BEN, NSF_SUF, NOAA_NIWA, ASRC_RSS. These instruments are now included in the reference algorithm to determine the reference spectrum in the following section.

\subsection{Reference Algorithm}

The reference algorithm is then applied to the instruments in the arena for the DOY 167 and 172. The reference algorithm is a reflection of how the instruments perform relative to the other instruments. The reference algorithm compares the individual observations for each instrument for each time and for each of the four wavelength bands to the spread medium. The spread medium is described in detail in the original paper but essentially is a weighted average of the instruments in the arena. The resulting instruments for the reference spectrum for DOY 167 include instruments IMUK_BEN, NSF_SUV, NOAA_NIWA. The reference spectrum for DOY 172 includes instruments USDA_U11, IMUK_BEN, NOAA_NIWA, and NSF_SUV. The reference spectrum is then used in the analysis of the solar irradiance for these two days in the following section.

\section{SYNCHRONIZED SOLAR IRRADIANCE}

\subsection{Introduction}

The major goal of the Intercomparison was to have all the instruments measure the spectral solar ultraviolet irradiance concurrently. The solar ultraviolet irradiance $E(\lambda)$ is the radiant energy, dQ, arriving on a horizontal surface per unit area, per unit time interval, for a given wavelength interval.

$$
E(\lambda)=\frac{d Q}{d A d t d \lambda}
$$

Uncertainties in the measurement primarily arise from the radiometric calibration, angular response error and method of correction, stray-light rejection, wavelength uncertainties, and the stability of the instrument under varying atmospheric conditions. Stray-light corrections, wavelength shifts, angular response corrections, and responsivity calculations were described in section 3. The following describes the data preparation and standardization of the spectra for differences in the instruments' slit-functions using two different methods to facilitate comparisons between measurements from the different instruments. The first method uses an algorithm that deconvolves and re-convolves to a 1-nm triangular slit function using a technique developed previously $[7,8]$. The solar irradiance determined from the deconvolution technique is compared to techniques used in previous intercomparisons that simply convolve the solar spectral irradiance with a $1-\mathrm{nm}$ triangular slit-function. The standardized spectral solar irradiances are compared to the reference spectrum for each day determined in section 5. The spectral solar irradiance from the "blind" protocol is compared using the participants' normal calibration procedures and again using the responsivity calculated with CUCF lamps and field calibrator. 

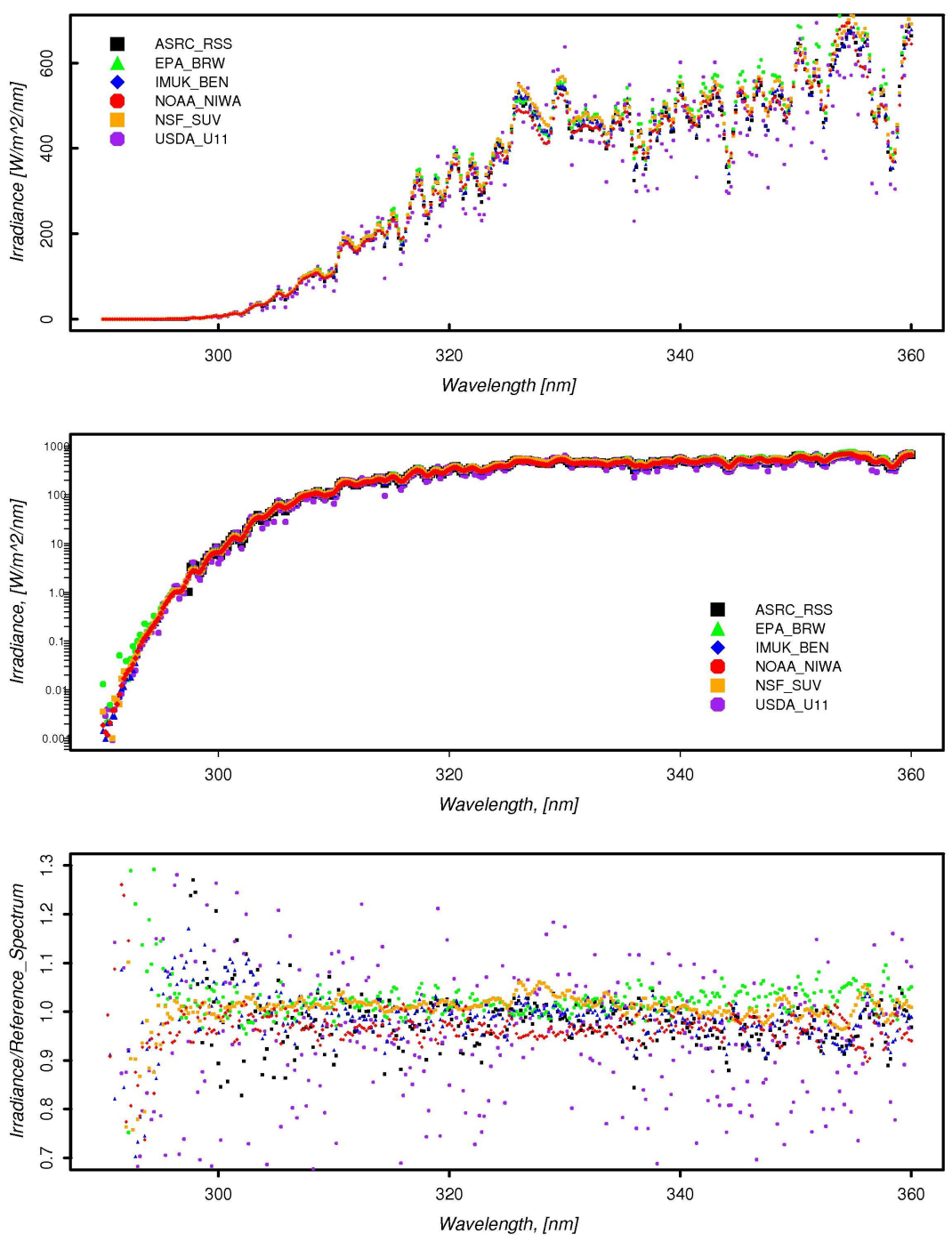

Fig. 6. Solar irradiance for DOY 167 at 19 [UTC] on a) a linear scale and b) logarithmic scale, and c) relative to reference spectrum measured by the instruments indicated in the legend on the day and time given in the panel.

\subsection{Data Preparation}

For the solar data from the instruments, the measured signal was corrected before the solar irradiance was calculated for dark and if needed for stray-light. For the EPA_BRW instrument, the signal was converted to a photon rate with dark subtraction and dead-time correction. Dark subtraction was performed on the NSF_SUV instrument by averaging all the signals at wavelengths shorter than $290 \mathrm{~nm}$ and subtracting this value from all the signals of the scan, which also corrects for stray-light if there is any. For the USDA_U11 instrument and for the NOAA_NIWA instrument, the average of the dark signals was obtained immediately before and after a synchronized scan and then subtracted from solar signal. For 
the ASRC_RSS instrument, the exposure time of the CCD array was set for a given time with the shutter open to measure the total irradiance signal, and then the exposure was set again while the shutter was closed to measure the dark signal. The dark signal was then subtracted from the total signal.

Stray light can result in relatively large signals at the shortest wavelengths for single monochromator instruments such as the EPA_BRW. For the EPA_BRW, stray-light subtraction was employed by subtracting the average signal for the shortest wavelengths from the signals at longer wavelengths. The stray-light rejection of the IMUK_BEN, NOAA_NIWA NSF_SUV, USDA_U11 instrument was sufficient and limited by the noise detection, and therefore no correction to the signals at the shortest wavelengths was necessary. Typical stray-light rejection values are given in Table 3 .

The procedure with the NSF_SUV is to transfer the spectral irradiance scale of the external $200 \mathrm{~W}$ lamp to the internal $45 \mathrm{~W}$ lamp from spectral scans of both lamps with the same voltage on the PMT. Different voltages are used for scans of the solar irradiance, and the responsivity of the instrument is dependent upon the high voltage. Therefore, the internal lamp is scanned at least daily at all PMT voltages that are used for solar measurements. To use the NIST irradiance scale with this procedure, the scale was transferred to the NSF external $200 \mathrm{~W}$ lamp from the scan of the NIST standard lamp at $800 \mathrm{~V}$, and this new scale for the external lamp was then used with scans of the internal $45 \mathrm{~W}$ lamp. The responsivity of the instrument at any voltage was determined from the scan of the $45 \mathrm{~W}$ lamp at the same high voltage that occurred closest in time to the scan of the solar irradiance. To maintain consistency with the NSF SUV procedure for responsivity, the responsivities used to calculate the solar irradiance were those determined closest in time to the synchronized scans.

\subsection{Results and Discussion}

\subsubsection{SHICrivm Algorithm versus standard convolution}

The individual instruments have bandwidths that range from $0.1 \mathrm{~nm}$ to $0.75 \mathrm{~nm}$ (Table 3). The differences in the bandwidths give spectral solar irradiance of different resolution that complicates the comparisons between the instruments. This can be seen in Fig. 6 that shows the spectral solar irradiance as a function of wavelength compared to the reference spectrum before standardization of the spectra for DOY 167 at 19 [UTC]. To facilitate comparison of the spectral solar irradiance between the instruments, the spectra need to be standardized to a common bandwidth. This paper uses two methods to standardize the spectra. The first method is fairly simple and convolves the solar spectra with a triangular slit function with a bandwidth slightly larger than the instrument with the largest bandwidth, in this case a 1-nm bandwidth. This is one of the methods used in the analysis of the spectral solar irradiance from the previous North American Intercomparisons. The second method uses an algorithm developed at RIVM in the Netherlands [7,8]. The method involves deconvolving the solar irradiance using a high-resolution extraterrestrial spectrum and then reconvolving the solar irradiance with a 1-nm triangular slit function. The extraterrestrial spectrum is based on data from the Kitt Peak Observatory and Atlas 3 and has a resolution of better than $0.005 \mathrm{~nm}$. The method has the additional advantage of correcting for possible wavelength shifts in the data by comparison of the structure in the solar spectra to the solar Fraunhofer structure as described in section $3.1[7,8]$. The algorithm has other features that help to identify outliers (e.g. spikes) in the spectral solar irradiance or weighted products.

Figure 7 shows a comparison of the spectral solar irradiance on DOY 172 and 17.0 [UTC] for a) the traditional method used previously, and b) the SHICrivm method used currently. The two standardization procedures for different instrumental slit-functions are comparable with negligible differences. The differences are less than $0.5 \%$ relative to the 
reference spectrum where part of this change is due to application of the wavelength shifts. This gives confidence in the method used in previous campaigns. However, the SHICrivm is the preferred method given it has the advantage of the choice to remove spikes and correct for wavelength errors before the standardization, which provides a means to separate the majority of the wavelength errors from other sources of error. In this intercomparison the instruments wavelength errors were better than $0.05 \mathrm{~nm}$ (Table 3).

DOY 172, 2003, 17 [UTC], $(\mathrm{SZA}=30.6)$

$1.0 \mathrm{~nm}$ Triangular Convolution - Participant Calibration

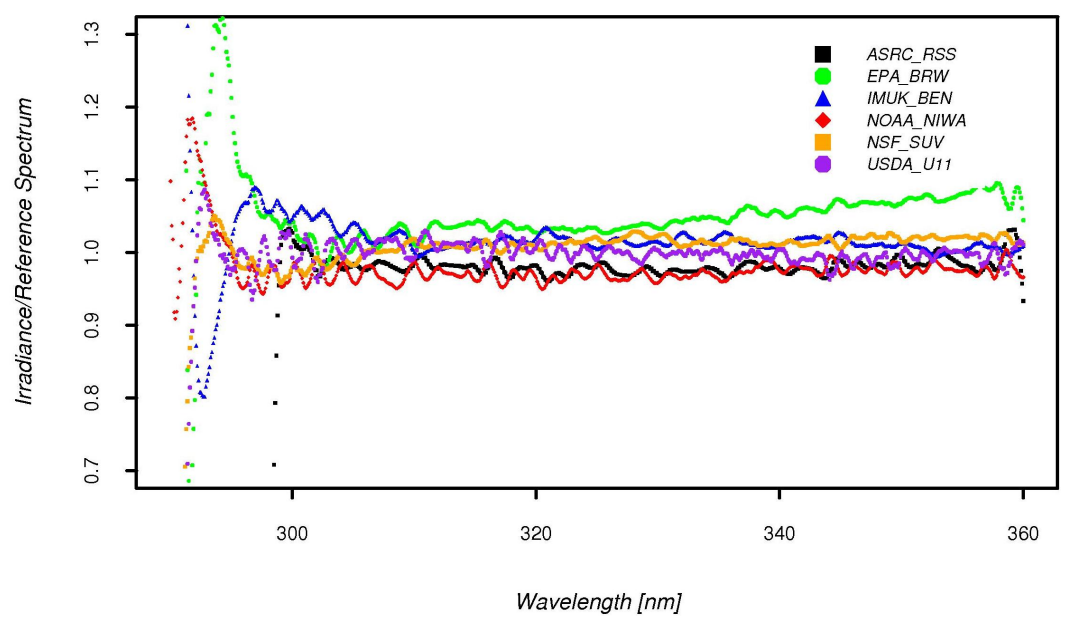

rivmSHIC Deconvolution Code - Participant Calibration

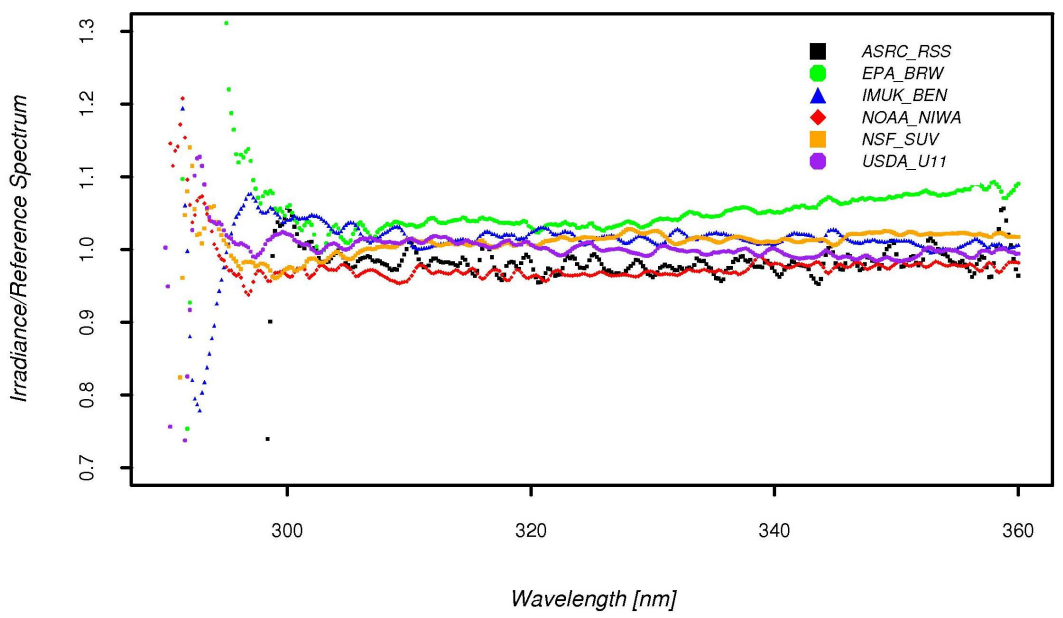

Fig. 7. Spectral solar irradiance for DOY 172 at 17 [UTC] $\left(30.6^{\circ}\right)$ using the participants calibration relative to the reference spectrum; where a) the solar irradiance is convolved with 1-nm triangular slit-function and b) the solar irradiance is deconvolved and standardized with a $1-\mathrm{nm}$ triangular slit-function by rivmSHIC method. 
DOY 172, 2003, 17 [UTC], (SZA = 30.6)

rivmSHIC Deconvolution Code - Participant Calibration

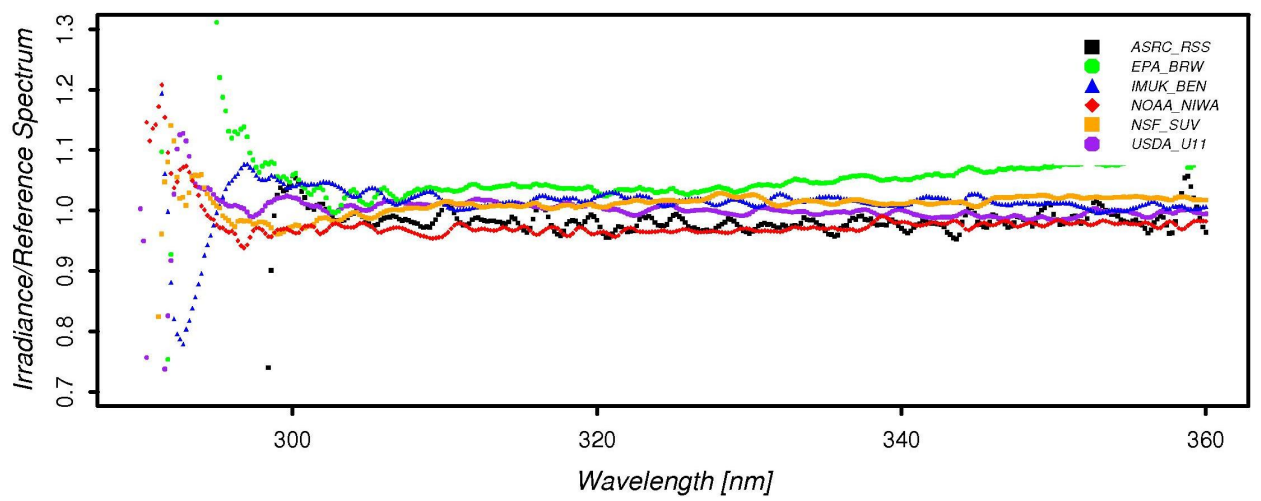

rivmSHIC Deconvolution Code - CUCF Calibration

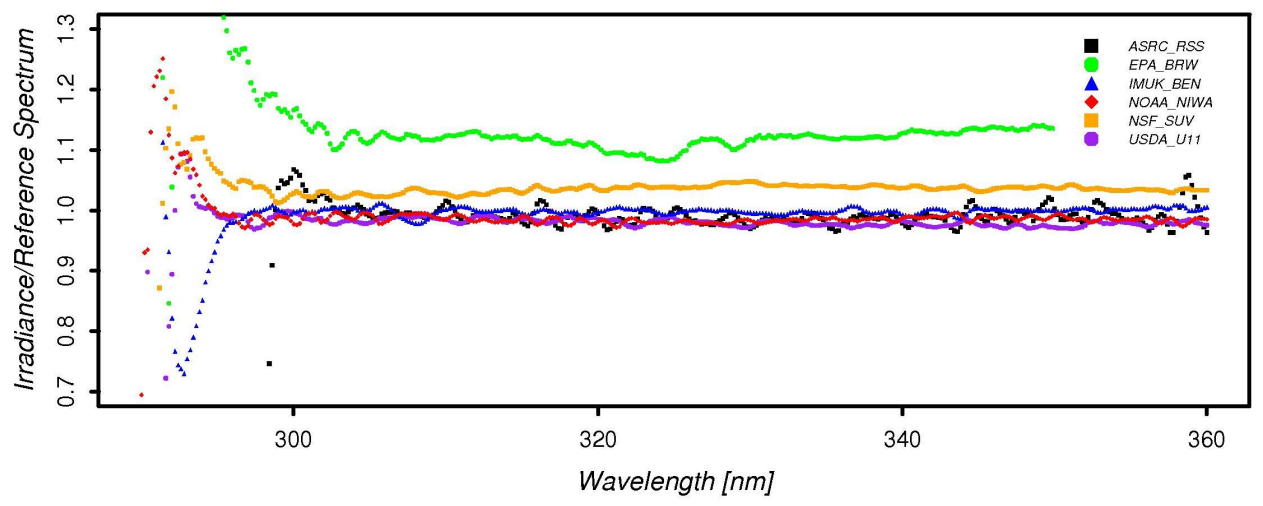

rivmSHIC Deconvolution Code - CUCF Calibration with EPA correction

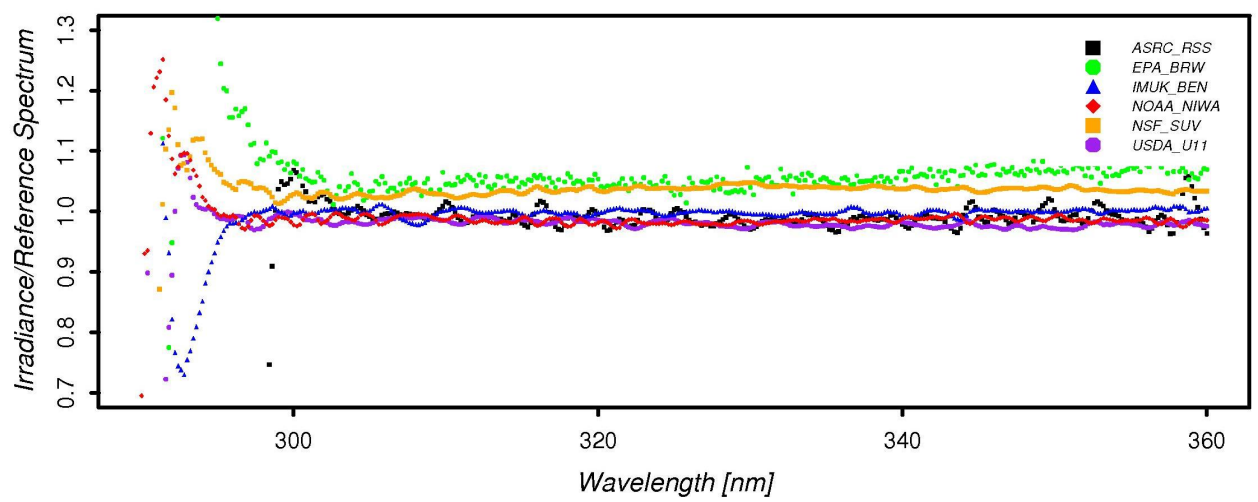

Fig. 8. Spectral solar irradiance for DOY 172 at 17 [UTC] standardized using the rivmsSHIC method as a function of wavelength for the instruments indicated in the legend relative to the reference spectrum; where the responsivity is determined a) using the participants lamps, b) uses the CUCF lamps; and c) is the same as b but the EPA_BRW data is corrected because of a calculation error. 


\subsubsection{Solar irradiance with Participants' Calibration and CUCF Calibration.}

The spectral solar irradiance using the participants' calibration lamps and procedures was provided "blind" to the organizers the following day from the measurement day for DOY 167 - 172. The exception was the ASRC_RSS spectrograph that was given additional time because it required routines to generate pseudo scans from the simultaneous measurements, but still adhered to the principle of the "blind" comparison. The spectral solar irradiance was generated again using the responsivity determined using a common set of calibration lamps from the CUCF including the CUCF field calibration unit as described in section 3 . The intent was to remove biases that may occur due to different calibration sources. Considering many of the instruments' calibrations can be traced to the CUCF, this was to avoid an unnecessary favorable bias in the results with instrument having a common calibration link. The USDA_U11, ASRC_RSS, NOAA_NIWA are calibrated by the CUCF on a regular basis. Here the calibration was performed prior to the start of the intercomparison by the CUCF with a separate set of three lamps (H-015, H-024, and H-028) than the set of lamps used for the full set of spectroradiometers for the CUCF calibration performed at the end of the intercomparison (H-025, H-027, H-030). Instruments from the EPA National UV Network that includes the instrument EPA_BRW are audited by the CUCF on a semi-annual basis, but use their own set of working lamps. The CUCF also provides calibrated horizontal lamps for the NSF UV Network, however these lamps were not used for the "participant calibration" of NSF_SUV. The only spectroradiometer with no link to the CUCF is the IMUK_BEN instrument.

The spectral solar irradiance submitted from the participants was deconvolved using the SHICrivm algorithm as described above and reconvolved using a 1-nm triangular band-pass. The spectral solar irradiance for each instrument relative to the reference spectrum as a function of wavelength for DOY 172, June 21, 2003, at 17.0 UTC is given in the top panel of Fig. 8 The 1 -sigma standard deviation is \pm 1.8 to $4.3 \%$ for $300-360 \mathrm{~nm}$. This is comparable to previous years using the CUCF calibration lamps. The second panel of Fig. 8 shows the solar irradiance with respect to the reference spectrum as a function of wavelength for the same date and time but using the CUCF calibration lamps. In this case when a single set of calibration lamps are used for the responsivity determination (see Table 5), the agreement is actually worse with a 1-sigma standard deviation of $\pm 3.9 \%$ to $6.9 \%$ for $300-360 \mathrm{~nm}$. In particular, the solar irradiance from the EPA_BRW instrument is significantly higher than the reference spectrum by $8.6 \%$ at $310 \mathrm{~nm}$. The EPA_BRW instrument was calibrated on DOY 164 using the participant's lamps and again on DOY 175 using the CUCF calibration lamp and field calibrator. The differences between the two responsivities are minor $(<1 \%)$. The EPA_BRW participants correct their data for the angular response but this would be the same from Fig. 8(a) to 8(b) [27]. They also correct for the temperature dependence of the responsivity that typically is $0.4-0.1 \% /{ }^{\circ} \mathrm{C}[28,29]$. However, the temperature difference between the two responsivity measurements is only $0.1^{\circ} \mathrm{C}$ and this cannot explain the difference observed from Fig. 8(a) to Fig. 8(b). The spectral solar irradiance for the EPA_BRW instrument is re-calculated from the spectral solar irradiance using the participant's calibration and recalculated by multiplying by the responsivity ratio from DOY 164 to 175 . The result is shown in Fig. 8(c) and gives a 1-sigma standard deviation of \pm 1.8 to $4.7 \%$ with respect to the reference spectrum from $300-360 \mathrm{~nm}$. This is closer to results observed during previous intercomparisons and to the participants' calibrations given in Fig. 8(a) [5]. The EPA participants believe there was a calculation error in their processing routines that needs to be evaluated. 
DOY 172, 2003, 17 [UTC], $($ SZA = 30.6)

rivmSHIC Code - Comparison between CUCF and Participant Calibration (EPA corrected data)

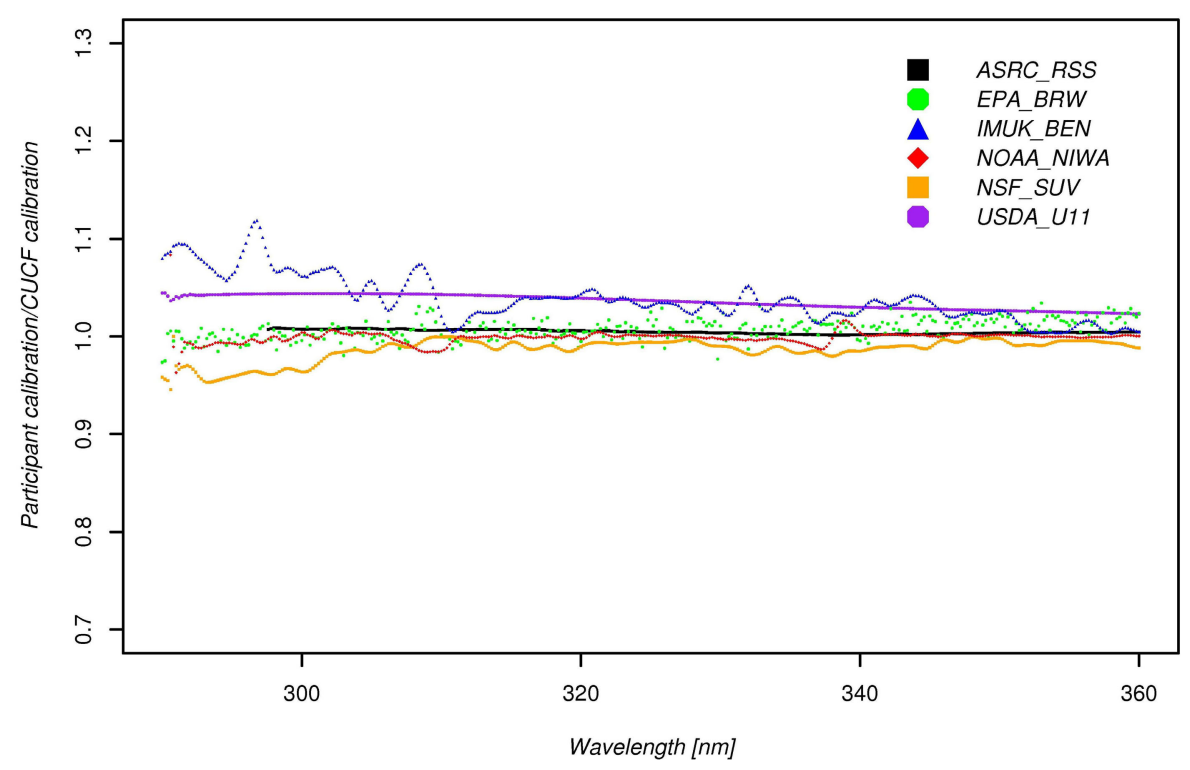

Fig. 9. Comparison of the spectral solar irradiance for DOY 172 at 17 [UTC] using the responsivity determined by the participants' lamps to the spectral solar irradiance using the responsivity determined using the CUCF calibration lamps. The corrected EPA_BRW data has been used here.

Differences between the spectral solar irradiance using responsivities determined using the participants' calibration lamps and the CUCF calibration lamps can also be seen in Fig. 9. Figure 9 compares the solar spectral solar irradiance using the responsivity determined using the participants' lamps versus the solar spectral solar irradiance calculated using the responsivity determined with the CUCF lamps and field calibrator. The EPA_BRW data used here is the corrected data. The largest differences when the calibration source changes are for the solar irradiance from the USDA_U11 and the IMUK_BEN, 4\% and 3\% at 310 $\mathrm{nm}$, respectively. The USDA_U11 is calibrated normally by the CUCF using CUCF lamps and field calibrator. This change cannot be attributed to changes in the irradiance scale during this period as shown in section 4 . The change in the responsivity has been attributed to the accumulation of dust and dirt on the Teflon diffuser. The change was observable after a significant weather front moved through with a heavy downpour, presumably cleaning the diffuser. The Teflon diffuser was cleaned with a spray of distilled water prior to the calibration on DOY 156. Subsequent studies have shown that the responsivity typically can change by $2-5 \%$ between when tested, then cleaned with distilled water and a soft brush, and tested again. There are several possible causes for differences in the solar irradiance using responsivities calculated using the CUCF lamps and the participants' lamps. These include but are not limited the uncertainty in the irradiance scale of the primary lamps from different national organizations, uncertainty in the transfer of the irradiance scale to the secondary or working lamps, transfer of the scale from the vertical to the horizontal, the stability or drift of 
the particular lamp, differences in conditions when the responsivity was determined versus the

time of the solar irradiance measurements. Results of an intercomparison of spectral irradiance from national laboratories gave results of $2-4 \%$ in the ultraviolet region. [30]. More recent studies of reference standards from European solar-ultraviolet laboratories gave differences of as much as $9 \%$ with an average difference of less than 3\% [31]. Uncertainty in the transfer of the irradiance scale to working horizontal lamps has been estimated at 1.6 to $0.9 \%$ for $280-400 \mathrm{~nm}$ [25]. The stability of the lamps used for the CUCF calibration are given in section 4 and are less than 1\% during the intercomparison. Other uncertainties include the temperature dependency in the responsivity and the correction of the data [28]; recent studies have looked at the temperature dependence of PTFE diffusers [32, 33]. Uncertainties in spectral solar irradiance from well-maintained spectroradiometers have been estimated at $\pm 6.3 \%-12.7 \%$ from the UVA to $300 \mathrm{~nm}$ [23]. One source of difference is that the IMUK_BEN responsivity is determined using an irradiance scale traceable to PhysikalischTechnische Bundesanstalt (PTB) whereas the other spectroradiometers' irradiance scales are traceable to the National Institute of Standards and Technology (NIST).

Figure 10 gives the solar irradiance DOY 167 for the six spectroradiometers relative to the reference spectrum for four wavelength bands as a function of solar zenith angle and time of day where the instruments have been calibrated using the participants calibration lamps and procedures and the four wavelength bands are at a) $290-305 \mathrm{~nm}$, b) $315-330 \mathrm{~nm}$, c) $330-345 \mathrm{~nm}$, and d) $345-360 \mathrm{~nm}$. For the shortest wavelength band, as expected the spread and 1-sigma standard deviation is the largest even at high sun $(> \pm 10 \%)$. The ASRC_RSS is especially poor in this short wavelength region $(>15 \%$ at high sun). The ASRC_RSS spectrograph instrument agrees well with the other spectral instruments for wavelengths longer than $300 \mathrm{~nm}$. The wavelength bands show in Figs. 10(b), (c) and (d) give $1-\sigma$ average deviations at noon of $2.5,2.9 \%$, and $4.1 \%$ respectively. Across the entire day the comparison between the instruments is less than $\pm 3.2 \%, \pm 3.1 \%$, and $\pm 4.3 \%$. These results are an improvement over previous Intercomparisons where there were more significant deviations at larger solar zenith angles, which is likely due to improvements in the angular response of the detectors and/or the corrections applied for the angular response error. For the wavelength band centered near $352.5 \mathrm{~nm}$, the solar irradiance measurements from the EPA_BRW instrument begin to deviate and measured approximately $8 \%$ higher than the other instruments close to noon. This is evident in the comparison between the responsivities measured by the CUCF versus the participants where the participant's responsivity becomes higher than the CUCF determined responsivity at longer wavelengths. This has been observed also during the CUCF audits for the NUVMC and the cause has not been identified. However, this does not explain why there is a solar zenith angle dependence to the deviation for this wavelength band and may be an indicator that the algorithm for temperature correction is not working properly. 
$167,2003-1.0$ nm Triangle - Participant Calibration
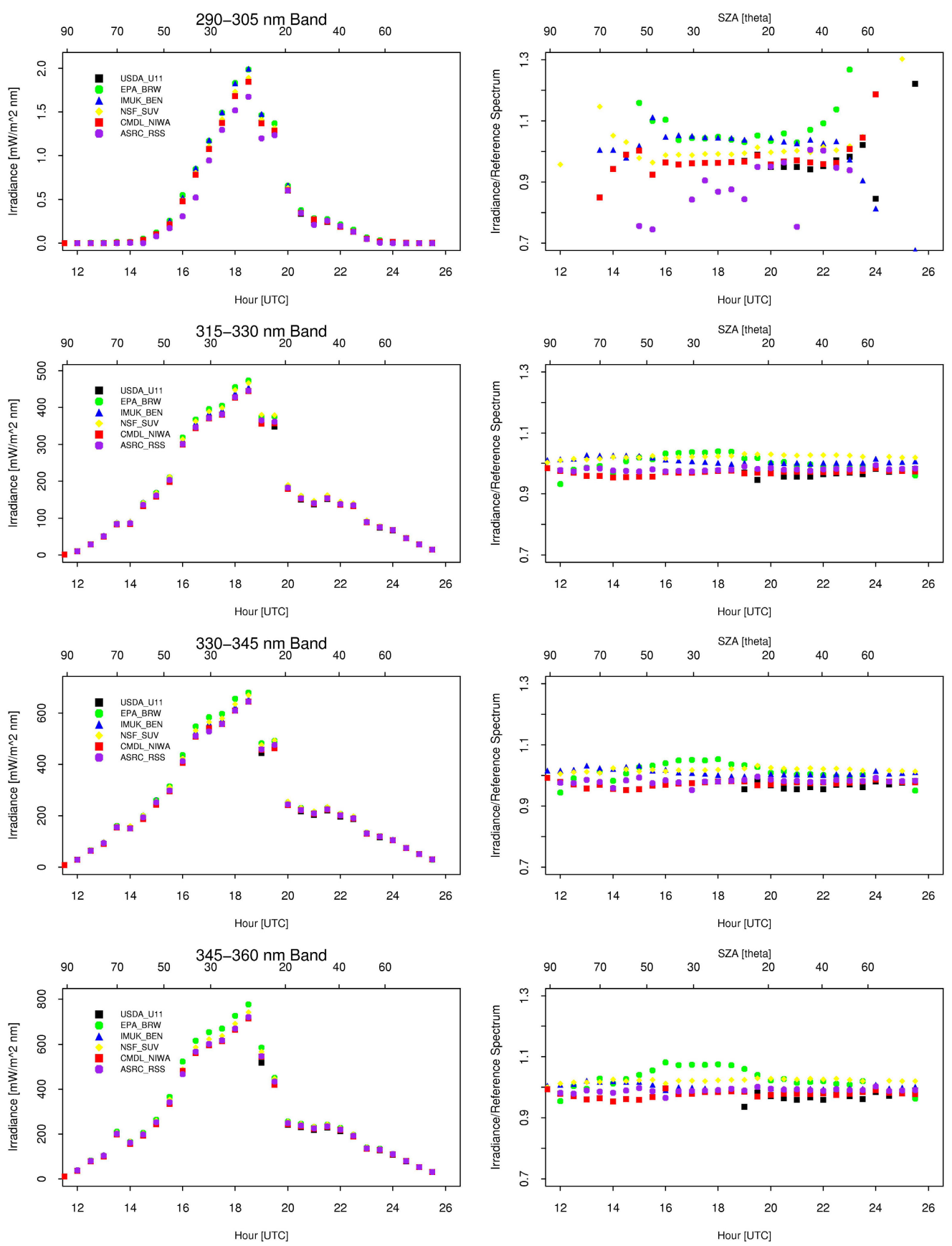

Fig. 10. The panels give the solar irradiance for DOY 167 relative to the reference spectrum as a function of time for the instruments indicated in the legend. 


\section{DATA PRODUCTS}

\subsection{Introduction}

In addition to measuring the spectral UV solar irradiance, the data can be weighted with specific action spectra to generate a weighted product, and some instruments have the additional capability depending on the design to derive other products, e.g. total $\mathrm{O}_{3}, \mathrm{SO}_{2}$, $\mathrm{NO}_{2}$, and aerosol optical depth. The weighted solar irradiance products depend on the spectral range of the instruments. The spectroradiometers at the intercomparison measured solar irradiance from $290-360 \mathrm{~nm}$. This wavelength range was chosen because it covers the spectral region in common among all the instruments. The full range capabilities of each instrument are given in Table 3. Each agency with UV instrumentation has their own individual goals and hence different priorities for products from the given instrumentation. Common products that have been developed by many of the participating agencies include total ozone and erythemally weighted solar irradiance. The next two sections compare total ozone and erythema between several of the participating instruments. The participants were instructed to use their existing algorithms that are described elsewhere [34, 35, 36, 37].

\subsection{Total Ozone}

The scanning spectroradiometers that measured total ozone during the intercomparison include the NSF_SUV and NOAA_NIWA. Details of the derivation have been given elsewhere but the instruments use some form of a differential wavelength technique to derive total ozone. Figures showing total ozone from the filter radiometers are compared to these two spectroradiometers are available from the NOAA CUCF ftp site (http://www.esrl.noaa.gov/gmd/grad/). Total ozone can be produced from measurements from the ASRC_RSS instrument but the algorithm was in its preliminary stages during the intercomparison and total ozone measurements were not provided to the organizers [36].

The NOAA_NIWA instrument is maintained by the Ozone and Water Vapor Group of the Global Monitoring Division of ESRL/NOAA. This group maintains 15 stations using the Dobson Ozone Spectrophotometer and is the World Dobson Ozone Calibration Centre under the Global Atmosphere Watch, which is responsible for over 100 instruments globally. During normal operation this instrument is located on the roof of the NOAA building in close proximity to one of their Dobson Spectrophotometers. Prior to being re-located to the Table Mountain Test Facility for the intercomparison, this instrument was compared to the Dobson spectrophotometer and agreed within 2 DU. Figure 11 gives the total ozone measurements for the two scanning spectroradiometers versus time of day for DOY $167-172$. The patterns of ozone changes are followed between the two instruments, but the disagreement between the two instruments is quite significant and on average 12 DU for DOY 167 the most cloud-free day. However, this includes all measurements regardless of cloud condition. Note that both instruments used total horizontal irradiance to derive ozone, which is generally a less accurate ozone measurement procedure than direct beam irradiance measurements. Some of the difference can also be explained by the different ozone and temperature vertical profiles used by the NIWA and BSI retrieval algorithms [14]. 

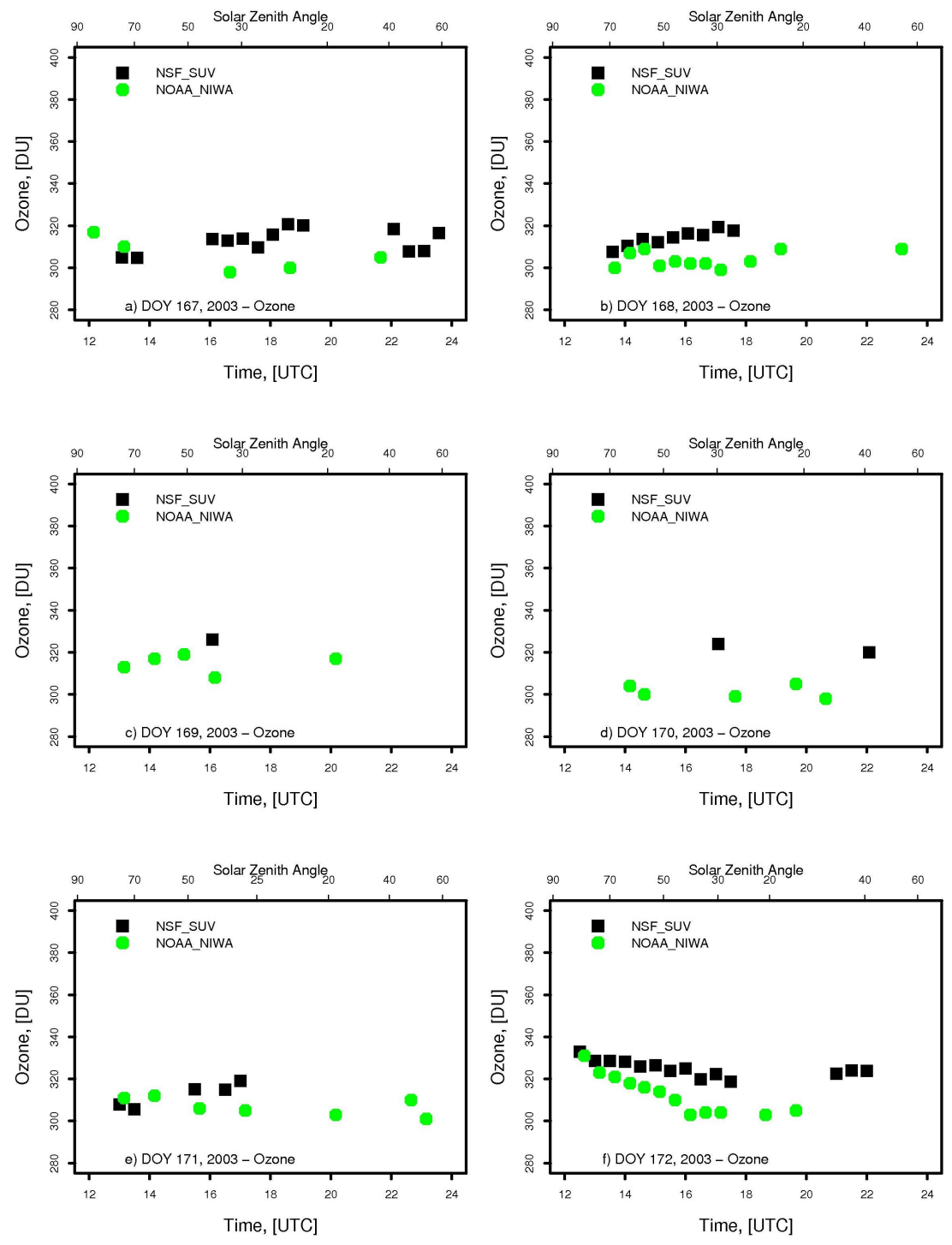

Fig. 11. Total ozone from NOAA_NIWA and NSF_BSI instruments.

\subsection{Erythema}

Erythema is the biologically weighted solar irradiance for skin reddening or sunburn [38] Because of the ubiquity of instruments designed to measure this quantity especially inexpensive broadband radiometers, erythema is often studied as the proxy for UV variability $[39,40]$. The entire set of participating instruments have the capability of measuring erythemally-weighted solar irradiance, but for the scanning spectroradiometers and spectrograph instruments currently only the EPA_BRW, NSF_SUV, and NOAA_NIWA routinely provide erythema from their managing agencies' web-sites. Figures are available on the CUCF ftp site that shows erythema from the spectrograph included here with four of the participating filter radiometers, i.e. two UV-MFRSR radiometers, one SERC filter radiometer, and a GUV-511 filter radiometer. The McKinlay-Diffey action spectrum [38] 
that is used here is the internationally accepted CIE erythema action spectrum and spans the wavelength range from $290-400 \mathrm{~nm}$.

In normal operation, the ASRC_RSS, IMUK_BEN, NOAA_NIWA, NSF_SUV, USDA_U11 have a spectral wavelength range that covers the full range of the CIE erythema action spectrum and the calculation of erythemally weighted solar irradiance is relatively straight forward. The Mark IV Brewer spectrophotometer (EPA BRW) used in the EPA UV Network has a wavelength range of $290-363 \mathrm{~nm}$, but routinely measures and provides erythema by using internal code of the Mark IV Brewer that mathematically extends the wavelength range from $363 \mathrm{~nm}$ to $400 \mathrm{~nm}$.

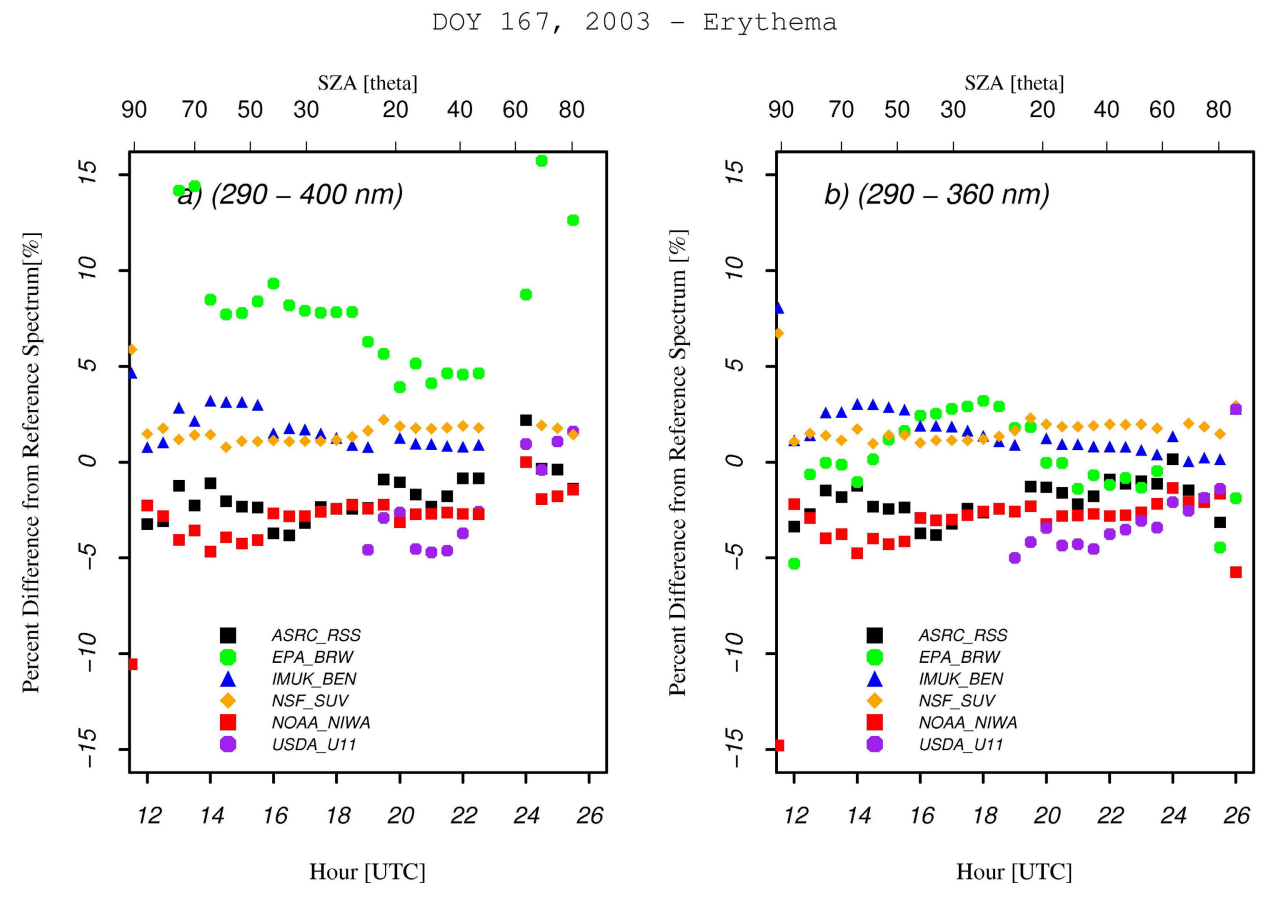

Fig. 12. a) Relative difference of erythemally weighted irradiance from each instrument indicated in the legend from erythemally weighted irradiance from the reference spectrum as a function of SZA for erythema from $290-400 \mathrm{~nm}$. b) Relative difference of erythemally weighted irradiance from each instrument indicated in the legend from erythemally weighted irradiance from the reference spectrum as a function of SZA for erythema from $290-360 \mathrm{~nm}$.

The protocol of the intercomparison covered the spectral range from $290-360 \mathrm{~nm}$, where each instrument used its own method for determining the solar irradiance from 360 $400 \mathrm{~nm}$. The NSF_SUV, IMUK_SUV, and NOAA_NIWA instruments measured the solar irradiance from $360-400 \mathrm{~nm}$ by either/or both increasing the step-size and decreasing the time between steps to achieve an extended wavelength scan before the start-time of the next scan. The USDA_U11 instrument used look-up tables from modeled clear-sky erythema values from $360-400 \mathrm{~nm}$ normalized to the measurements from $355-360 \mathrm{~nm}$. The UV_RSS is a spectrograph measuring the solar irradiance spectrum from $290-400 \mathrm{~nm}$ at all wavelengths simultaneously. The UV RSS uses the pseudo scan calculated for section 6 , but uses the extended region out to $400 \mathrm{~nm}$. The UV_RSS determines the instantaneous 
erythema for the erythema spectral range $(290-400 \mathrm{~nm})$, which can be compared more easily to the filter radiometers' erythema calculations.

The protocol of the intercomparison was to provide "blind" erythemally weighted irradiance to the organizers using the participant's calibration. Figure 12(a) gives the erythemally weighted irradiance as provided from the participants from the spectroradiometers indicated in the panels as a function of time for DOY 167. The instruments agreed fairly well with the exception of EPA_BRW that was measuring high with respect to the other instruments. The EPA_BRW erythema data were corrected by the participants for temperature and angular response, and the extended wavelength range from $363-400 \mathrm{~nm}$. The intercomparison protocol for obtaining synchronized scans at $3 \mathrm{sec}$ steps every $0.2 \mathrm{~nm}$ necessitated a change in the operating routine of the EPA_BRW instrument and the internal code used in normal operation for calculating erythema was not implemented. It is not clear why the erythema from the EPA_BRW is higher than the erythema from the other instruments because this is not the case for the spectral solar irradiance using the participant's calibration before the weighting by the erythema action spectrum and addition of the extended wavelength region to $400 \mathrm{~nm}$. Possibly the method and additional uncertainty for estimating the extending the wavelength region is incorrect. To circumvent the differences in the routines to extend the wavelength range from $360-400 \mathrm{~nm}$, Fig. 12(b) gives the solar irradiance measurements from section 6 weighted with the CIE erythema action spectrum from $290-360 \mathrm{~nm}$. Here the agreement is better $( \pm 2.6 \% 1 \sigma$ at 19 [UTC] $)$ and also a better indicator of the capabilities of the instruments.

\section{CONCLUSIONS}

This year there was a return to a blind intercomparison of spectral solar irradiance and the comparison between instruments agreed very well, i.e. DOY 172 at 17.0 UTC (SZA $=30.6$ ${ }^{\circ} \mathrm{C}$ ) has a 1-sigma standard deviation is \pm 1.8 to $4.3 \%$ for $300-360 \mathrm{~nm}$. Using the responsivity determined with the CUCF lamps the comparison between instruments is \pm 1.8 to $4.7 \%$ for $300-360 \mathrm{~nm}$ when using EPA corrected data. The original EPA_BRW data was $8 \%$ high with respect to the reference spectrum and was attributed to a calculation error in the processing routines. The blind comparison using the participant's calibration procedures agreed at the same level if not slightly better than using the responsivity determined with lamps calibrated by the CUCF. This is surprising given that the solar irradiance calculated using the CUCF calibrated lamps reduced sources of uncertainties with a single irradiance transfer scale, but are still within estimates of achievable uncertainties for these instruments [23]. The blind results are an improvement over previous years and indicate the advancement of the participating agencies in the calibration routines and measurement accuracy. In addition, the instruments agreed better across a range of solar zenith angles compared to previous years. This is in part due to more sophisticated instrumentation with better designed angular responses, and the implementation of routines to correct for angular response errors.

In this intercomparison, there was a change in how the reference spectrum was determined. This year, a reference and arena algorithm was used to determine the reference spectrum as outlined in a paper by Gardiner et al. [6]. This algorithm has been used successfully in several European Intercomparisons. Weaknesses of the reference algorithm are that the method does not work as well with a smaller sub-set of instruments. In the original text there is a requirement to have a minimum of 4 instruments, since in this case there are only 6 instruments the reference algorithm steps are likely to proceed to level 3, which has large acceptance range to be included in the reference set. However, this method is preferred because it provides an unbiased means of determining the reference spectrum.

The spectral irradiance responsivity of the instruments was determined with the CUCF horizontally calibrated $1000 \mathrm{~W}$ lamps using the CUCF field calibrator. The spectral 
irradiance scale of the lamps was checked against the CUCF primaries before and after the intercomparison on DOY 181. Lamps H-025 and H-027 did not have appreciable change in their irradiance scale during the intercomparison period for the spectral range from $290-400$ $\mathrm{nm}$ (average of $<0.5 \%$ ). However, the irradiance scale of lamp H-030 changed by approximately $0.9 \%$. Lamp H-025 is used for the responsivity determinations for the solar irradiance calculations tied to the CUCF calibration. The uncertainty in the absolute lamp irradiance scale is approximately $1.6 \%$ and $0.9 \%$ for $290-400 \mathrm{~nm}$ [25].

Synchronized solar irradiance scans from $290 \mathrm{~nm}$ to $360 \mathrm{~nm}$ were performed every halfhour during the Intercomparison. Because the instruments had different bandwidths, the measured irradiances were convolved to common a bandwidth by using both a $1-\mathrm{nm}$ triangular slit scattering function and using the SHICrivm algorithm. The SHICrivm algorithm deconvolves the solar spectra using a high resolution extraterrestrial spectrum and then reconvolves the solar irradiance with a 1-nm triangular band-pass. The SHICrivm method also corrects the data for wavelength shifts using solar Fraunhofer structure. The two techniques are compared for spectral solar irradiance measured at 17 UTC, on DOY 172, 2003. The agreement among the convolved irradiances was described by their relative difference from the reference spectrum determined by the technique devised by Gardiner et al. [6]. The relative standard deviation in the solar irradiance convolved with a triangular slit-scattering function between the spectral instruments was within $\pm 3.0 \%$ at $310 \mathrm{~nm}$ (1sigma) for high sun at 17 UTC, DOY 172. Using the SHICrivm code the relative standard deviation was also within $\pm 2.5 \%$ for the same time. The differences are minor and indicate that the instruments are doing very well with regard to wavelength stability and correction.

It should be mentioned that the Intercomparison format did not show all the benefits of each instrument. For instance, the ASRC_RSS is capable of measuring all wavelengths simultaneously, which is desirable when investigating a rapidly changing atmosphere such as cloud effects on solar irradiance. This same instrument has a rotating shadowband feature capable of measuring the total irradiance and the diffuse beam, and therefore retrieving the direct beam. Several of the instruments have an extended wavelength range, which is useful for many applications in atmospheric research. For example, the NSF_SUV instrument is capable of measuring irradiance out to $700 \mathrm{~nm}$; IMUK_BEN is capable of measuring out to $1050 \mathrm{~nm}$; NOAA_NIWA instrument is capable of measuring out to $450 \mathrm{~nm}$.

\section{Acknowledgments}

Operation of the National Science Foundation's Polar Ultraviolet Monitoring Network, along with participation in this Intercomparison, was funded from Antarctic Support Associates at the National Science Foundation, Office of Polar Programs. Operation of the National Ultraviolet Monitoring Network, along with participation in this Intercomparison, was funded through the U.S. Environmental Protection Agency Assistance. Development of the U111 Ultraviolet Scanning Radiometer, participation in this Intercomparison, and operation of the USDA UV Network was funded by the US Department of Agriculture UV-B Monitoring and Research Program through contracts 2003-34263-13509 and 2004-34263-14270 under the direction of Dr. Daniel Schmoldt.

\section{References}

[1] United Nations Environment Programme (UNEP), Environmental Effects of Ozone Depletion and its Interaction with Climate Change: 2006 Assessment, Ed. J. van der Leun, J. F. Bornman, X. Tang, http://www.unep.org/ozone (2006). 
[2] A. Thompson, E. A. Early, J. DeLuisi, P. Disterhoft, D. Wardle, J. Kerr, J. Rives, Yongchen Sun, T. Lucas, T. Mestechkina, and P. Neale, "The 1994 North American interagency intercomparison of ultraviolet monitoring spectroradiometers," J. Res. Natl. Inst. Stand. Technol. 102, 279-322 (1997).

[3] E. A. Early, Thompson, C. Johnson, J. DeLuisi, P. Disterhoft, D. Wardle, E. Wu, W. Mou, Yongchen Sun, T. Lucas, T. Mestechkina, L. Harrison, J. Berndt, and D. Hayes, "The 1995 North American interagency intercomparison of ultraviolet monitoring spectroradiometers," J. Res. Natl. Inst. Stand. Technol. 103, 15-62, (1998).

[4] E. A. Early, A. Thompson, C. Johnson, J. DeLuisi, P. Disterhoft, D. Wardle, E. Wu, W. Mou, J. Ehramjian, J. Tusson, T. Mestechkina, M. Beaubien, J. Gibson, and D. Hayes, "The 1996 North American interagency intercomparison of ultraviolet monitoring spectroradiometers," J. Res. Natl. Inst. Stand. Technol. 103, 449-482 (1998).

[5] K. Lantz, P. Disterhoft, E. Early, A. Thompson, J. DeLuisi, P. Kiedron, L. Harrison, J. Berndt, W. Mou, T. J. Erhamjian, L. Cabausua, J. Robertson, D. Hayes, J. Slusser, D. Bigelow, G. Janson, A. Beaubien, and M. Beaubien, "The 1997 North American interagency intercomparison of ultraviolet monitoring spectroradiometers," J. Res. Natl. Inst. Stand. Technol. 107, 19-62 (2002).

[6] B. J. Gardiner, and P. J. Kirsch, "Intercomparison of ultraviolet spectroradiometers, Ispra, Italy 24 - 25 May, 1995," pp. 68 - 151, A. Webb Ed., "Advances in solar ultraviolet spectroradiometry," Air Pollution Research Report 63 (1997).

[7] H. Slaper, H. Reinen, M. Blumthaler, M. Huber, and F. Kuik, "Comparing groundlevel spectrally resolved solar UV measurement using various instruments: A technique resolving effects of wavelength shift and slit width," Geophys. Res. Lett. 22, 2721-2724 (1995) [doi:10.1029/95GL02824].

[8] H. Slaper, "Methods for intercomparing instruments," pp. 154 - 164, A. Webb Ed., Advances in solar ultraviolet spectroradiometry, Air Pollution Research Report 63, (1997).

[9] P. A. Jansson, Deconvolution with Applications in Spectroscopy, pp. 8-10, Academic Press, San Diego, CA (1984).

[10] E. A. Early, and A. Thompson, "Irradiance of horizontal quartz-halogen standard lamps," J. Res. Natl. Inst. Stand. Technol. 101, 141 (1996).

[11] P. Disterhoft, "Stability characteristics of $1000 \mathrm{~W}$ FEL-type QTH lamps during the seasoning and screening process," Proc. SPIE 5886, p58860G (2005) [doi:10.1117/12.614584].

[12] D. S. Bigelow, J. R. Slusser, A. F. Beaubien, and J. H. Gibson, "The USDA ultraviolet radiation monitoring program," Bull. Amer. Meteor. Soc. 79, 601-615 (1998) [doi:10.1175/1520-0477].

[13] A. F. Bais, B. G. Gardiner, H. Slaper, M. Blumthaler, R. McKenzie, A.R. Webb, G. Seckmeyer, B. Kjeldstad, T. Koskela, P. J. Kirsch, J. Grobner, J. B. Kerr, S. Kazadzis, K. Leszczynski, D. Wardle, W. Josefsson, C. Brogniez, D. Gillotay, H. Reinen, P. Weihs, T. Svenoe, P. Eriksen, F. Kuik, and A. Redondas, "SUSPEN intercomparison of ultraviolet spectroradiometers," J. Geophys. Res. 106 (D12), 12509-12525 (2001)[doi:10.1029/2000JD900561].

[14] G. Bernhard, R. McKenzie, M. Kotkamp, S. Wood, C. Booth, J. Erhamjian, P. Johnston, and S. Nichol, "Comparison of ultraviolet spectroradiometers in Antarctica," J. Geophys. Res. 113, D14310 (2008) [doi:10.1029/2007JD009489].

[15] P. Kiedron, L. Harrison, J. Berndt, J. Michalsky, and A. Beaubien, "Specification and Performance of UV Rotating Shadowband Spectroradiometer," Proc. SPIE 4482, 249-258 (2001) [doi:10.1117/12.452925]. 
[16] L. Harrison, J. Berndt, J. Michalsky, and A. Beaubien, "USDA reference spectroradiometric network: current performance and operational experience," Proc. SPIE 4482, 23-37 (2001) [doi:10.1117/12.452934].

[17] S. Wuttke, G. Bernhard, J. Ehramjian, R. McKenzie, P. Johnston, M. O’Neill, and G. Seckmeyer, "New spectroradiometers complying with the NDSC standards," $J$. Atmos. Ocean. Tech. 23 (2), 241-251 (2006) [doi:10.1175/JTECH1826.1]

[18] L. Harrison, M. Beauharnois, J. Berndt, P. Kiedron, J. Michalsky, and Q. Min, "The rotating shadowband spectroradiometer (RSS) at SGP," Geophys. Res. Lett. 26, 1715-1718 (1999) [doi:10.1029/1999GL900328].

[19] L. Harrison, J. Michalsky, and J. Berndt, "Automated multi-filter rotating shadowband radiometer: an instrument for optical depth and radiation measurements," Appl. Optic. 33, 5118-5125 (1994).

[20] G. Bernhard, C. R. Booth, J. C. Ehramjian, and V. V. Quang, NSF Polar Programs UV Spectroradiometer Network 2004-2005 Operations Report Volume 14.0, Biospherical Instruments Inc., San Diego, CA (2006).

[21] G. Seckmeyer, "Spektralradiometer fuer die oekologische Pflanzenforschung," Licht 41, 7-8 (1989).

[22] M. Beauharnois, P. Kiedron, and L. Harrison, "The USDA high-resolution UV radiation network; maintenance, calibration, and data tools," Proc. SPIE 5545, 90101 (2004) [doi:10.1117/12.559504].

[23] G. Bernhard, G. Seckmeyer, Uncertainty of measurements of spectral solar UV irradiance, J. Geophys. Res. 104, 14321-14345 (1999) [doi:10.1029/1999JD900180].

[24] C. J. Sansonetti, M. L. Salit, and J. Reader, "Wavelengths of spectral lines in mercury pencil lamps," Appl. Opt. 35, 74 (1996).

[25] E. A. Early, A. Thompson, and P. Disterhoft, "A field calibration unit for ultraviolet spectroradiometers," Appl. Opt. 37, 6664-6670 (1998) [doi:10.1364/AO.37.006664].

[26] K. Lantz, P. Disterhoft, J Slusser, W Gao, J Berndt, G Bernhard, R Booth, J Ehramjian, L Harrison, G Janson', P Johnston ${ }^{\mathrm{d}}$, P Kiedron, R McKenzie, M Kimlin, P Neale, M. O’Neill , V. Quang, G. Seckmeyer, T. Taylor, and S. Wuttke, "Determination of the reference spectrum and instrument descriptions for the 2003 North American Interagency intercomparison of ultraviolet spectroradiometers," NOAA Technical Memorandum., NOAA-TM-OAR-ESRL (2008).

[27] J. Sabburg, J. E. Rives, R. S. Meltzer, T. Talyor, Schmalzle, S. Zheng, N. Huang, A. Wilson, and P. M. Udelhofen, "Comparisons of corrected daily-integrated erythemal UVR data from the U.S. EPA/UGA network of Brewer spectroradiometers with model and TOMS-inferred data," J. Geophys. Res. 107 (D23), 4676(2002). [doi:10.1029/2001JD001565].

[28] E. Weatherhead, D. Theisen, A. Stevermer, J. Enagonio, B. Rabinovitch, P. Disterhoft, K. Lantz, R. Meltzer, J. Sabburg, J. DeLuisi, J. Rives and J. Shreffler, "Temperature dependence of the Brewer ultraviolet data," J. Geophys. Res. 106, 13121-13129 (2001) [doi:10.1029/2001JD000625].

[29] T. Taylor and M. Kimlin, "Temperature Dependence of a Brewer Spectrophotometer," Department of Physics and Astronomy, University of Georgia, Athens, USA, internal document, (2002).

[30] J. H. Walker, R. D. Saunders, J. K. Jackson, and K. D. Mielenz, "Results of a CCPR intercomparison of spectral irradiance measurements by national laboratories," $J$. Res. Natl. Inst. Stand. Technol. 96, 647 - 668 (1991).

[31] J. Grobner, D. Rembges, A. F. Bais, M. Blumthaler, T. Cabot, W. Josefsson, T. Koskela, T. M. Thorseth, A. R. Webb, and U. Wester, "Quality assurance of 
reference standards from nine European solar-ultraviolet monitoring laboratories," Appl. Optic. 41, 4278 - 4282 (2002) [doi:10.1364/AO.41.004278].

[32] R. L. McKenzie., J. Badosa, M. Kotkamp, and P. V. Johnston, "Effects of the temperature dependence in PTFE diffusers on observed UV irradiances," Geophys. Res. Lett. 32, L06807 (2005) [doi:10.1029/2004GL022268].

[33] L. Ylianttila. and J. Schreder, "Temperature effects on PTFE diffusers," J. Opt. Materials 27, 1811 - 1814 (2005) [doi:10.1016/j.optmat.2004.11.008].

[34] G. Bernhard, C. R. Booth, and R. D. McPeters., "Calculation of total column ozone from global UV spectra at high latitudes," J. Geophys. Res. 108 (D17), 4532 (2003) [doi:10.1029/2003JD003450].

[35] W. Gao, J. Slusser, J. Gibson, G. Scott, D. Bigelow, J. Kerr, and B. McArthur, "Direct-sun column ozone retrieval by the ultraviolet multifilter rotating shadowband radiometer and comparison with those from Brewer and Dobson spectrophotometers," Appl. Opt. 40, 3149-3155 (2001) [doi:10.1364/AO.40.003149].

[36] P. Kiedron, L. Harrison, J. Schlemmer, and M. Beauharnois "Ozone and aerosol optical depth retrievals with UV rotating shadowband spectroradiometer (RSS)," Proc. SPIE 5886, 58860G (2005) [doi: 10.1117/12.613200].

[37] M. Kimlin, J. Slusser, K. A. Schallhorn, K. Lantz, and R. S. Meltzer, "Comparison of ultraviolet data from collocated instruments from the U.S. EPA Brewer spectrophotometer network and the U.S. Department of Agriculture UV-B monitoring and research program," Opt. Eng. 44(4), 041009 (2005) [doi:10.1117/1.1885470].

[38] A. F. McKinlay and B. L. Diffey, "A reference action spectrum for ultraviolet induced erythema in human skin," Commission International de l'Eclairage (CIE), Research Note, 6, 17-22(1987).

[39] R. L. McKenzie, P. J. Aucamp, A. F. Bais, L. O. Bjorn, and M. Ilyas, "Changes in biologically-active ultraviolet radiation reaching the Earth's surface," Photochem. Photobiol. Sci. 6 (3), 218-231, (2007) [doi:10.1039/b700017k].

[40] R. L. McKenzie R, D. Smale, and M. Kotkamp, "Relationship between UVB and erythemally weighted radiation," Photochem. Photobiol. Sci. 3 (3), 252-256 (2004) [doi: $10.1039 / \mathrm{b} 312985 \mathrm{c}$ ]. 